Camilo Esteban Cabra Salinas Estudiante de la Maestría en Tecnologías de la Información para el Negocio (MBIT) de la Universidad de los Andes Ingeniero industrial de la Universidad Distrital Francisco José de Caldas Colombia [ce.cabra@uniandes.edu.co]

Diego Alberto Rodríguez Vela Estudiante de la Maestría en Tecnologías de la Información para el Negocio (MBIT) de la Universidad de los Andes Ingeniero de sistemas de la Universidad Pedagógica y Tecnológica de Colombia Colombia [da.rodriguezv@uniandes.edu.co]

Carlos Javier Castellanos Parra Estudiante de la Maestría en Tecnologías de la Información para el Negocio (MBIT) de la Universidad de los Andes Especialista en Seguridad de la Información de la Universidad de los Andes Colombia [javier_caspar@uniandes.edu.co]

Cesar Ricardo Rojas Torres Estudiante de la Maestría en Tecnologías de la Información para el Negocio (MBIT) de la Universidad de los Andes Ingeniero de sistemas de la Universidad Autónoma de Colombia Colombia [cr.rojas@uniandes.edu.co]

Cristhiam Forero Reina Estudiante de la Maestría en Tecnologías de la Información para el Negocio (MBIT) de la Universidad de los Andes Ingeniero de sistemas de la Universidad EAN Colombia [c.foreror@uniandes.edu.co]

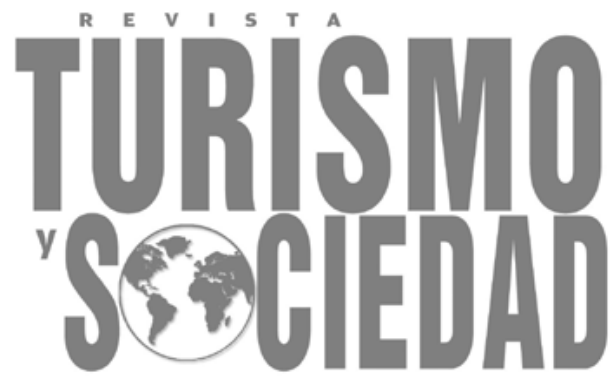

\section{PLAN DE TRANSFORMACIÓN DIGITAL PARA LA PROMOCIÓN TURÍSTICA EN EL VICEMINISTERIO DE TURISMO. CASO DE ESTUDIO: DEPARTAMENTO DE BOYACÁ 1}

\author{
DIGITAL TRANSFORMATION \\ PLAN FOR TOURISM \\ PROMOTION IN THE VICE \\ MINISTRY OF TOURISM. CASE \\ STUDY: DEPARTMENT OF \\ BOYACÁ
}

\section{Resumen}

Este artículo busca divulgar la metodología con la cual se construyó el Plan de Transformación Digital de la institución pública del Gobierno colombiano encargada de promover y articular el sector turístico en Colombia, denominada Viceministerio de Turismo. Este Plan se fundamentó en la arquitectura de negocio del sector (Kale, 2019) y en los objetivos estratégicos del Plan de Gobierno de Colombia a 2022 (Plan Nacional de Desarrollo) (DNP, 2019) y del Plan Sectorial de Turismo (Mincit, 2019). Como caso de estudio se seleccionó el departamento de Boyacá debido a su potencial turístico. En esta región se consultó a la población sobre la orientación de la transformación que deseaban vivir y sus necesidades de promoción turística. Los resultados de este trabajo se encuentran plasmados en el desarrollo de

\footnotetext{
1 Para citar el artículo: Cabra, C., Rodríguez, D., Castellanos, C., Rojas, C. y Forero, C. (2021). Plan de Transformación Digital para la Promoción Turística en el Viceministerio de Turismo. Caso de estudio: departamento de Boyacá. Turismo y Sociedad, XXVIII, pp. 151-185. DOI: https://doi.org/10.18601/01207555. $\mathrm{n} 28.08$
}

Fecha de recepción: 21 de mayo de 2019

Fecha de modificación: 16 de agosto de 2020

Fecha de aceptación: 31 de enero de 2020

Fecha de aceptacion: 31 de enero de 2020 
un prototipo funcional con el cual se buscó materializar el proceso transformador que genera el turismo en la economía del país, dada la importancia de las tecnologías de la información en la vida cotidiana de los ciudadanos.

Palabras clave: Transformación digital, políticas públicas, estrategia, turismo, tecnologías de la información y arquitectura de negocio.

\section{Abstract}

This article seeks to show the methodology with which the Digital Transformation Plan was designed for the public institution of the Colombian Government responsible for promoting and articulating the tourism sector in Colombia. In Colombia this is called the Vice-Ministry of Tourism. This was based on the Business Architecture of the sector (Kale, 2019), in accordance with the strategic objectives of the Government Plan of Colombia to 2022 (DNP, 2019) and the Tourism Sector Plan (Mincit, 2019). This employed the Department of Boyacá as a case study due to its tourist potential. In this region, the population was asked about the type of transformation they wished to experience and their touristic promotional needs. The results of this work are reflected in the development of a functional prototype, which sought to identify the transformative process generated by tourism in the economy of the country given the importance of information technologies in the daily lives of citizens.

Keywords: Digital transformation, public policies, strategy, tourism, information technology and business architecture.

\section{Introducción}

Este trabajo consiste en la materialización de la visión estratégica contenida en el Plan Nacional de Desarrollo 2018-2022 (DNP, 2019) del Gobierno de Colombia, en el que se despliegan una serie de objetivos macro que son detallados para el sector turismo en el Plan Sectorial de Turismo "Por un turismo que construye país" (Mincit, 2019); en él se evidencia la necesidad de poder exponer a la comunidad herramientas tecnológicas que permitan mejorar la competitividad del sector.

La metodología que se llevó a cabo en el estudio se fundamentó en la generación de una arquitectura de negocio (Kale, 2019) en la cual se analizó el escenario de negocio comprendido por los datos del Registro Nacional de Turismo (RNT), inventarios y corredores turísticos, y por medio del cual se diagnosticó la situación actual desde la óptica de negocio del sector en el ámbito público. Con base en dicho diagnóstico, se identificaron los motivadores de negocio y las brechas que se deben cerrar para llegar a la situación deseada, cierre que podría darse de manera eficiente y competitiva gracias a las tecnologías de la información.

A partir de las brechas encontradas se identificaron iniciativas desde el desarrollo de software que le otorgarían valor al sector turístico para el cumplimiento de sus objetivos sectoriales. Estas iniciativas fueron agrupadas en estrategias de transformación digital, las cuales fueron descritas, tipificadas, cuantificadas, costeadas y ordenadas en el tiempo para su posible ejecución. Cada una de estas estrategias de transformación lleva el nombre de un ave representativa de Colombia. 
Con el fin de poder llegar a un mayor nivel de profundidad y tener mayor certeza sobre la implementación de tales estrategias, se profundizó en la creación del Sistema Integrado de Turismo (SIT) denominado Estrategia Colibrí, en el que se planteó la transformación del negocio y se generó un prototipo funcional que representa la interactividad para el usuario funcional. Además, se diseñó una hoja de ruta que respondiera a los plazos de la visión de gobierno, con el fin de aprovechar la tecnología en una economía cada vez más digitalizada.

Este artículo tiene como objetivo brindar a la comunidad académica una ruta probada de la ejecución de la transformación digital desde una visión de gobierno, con el fin de que se apalanquen los sectores económicos para impulsar la economía de los países en desarrollo a tasas de alto crecimiento.

\section{Metodología}

La metodología que se siguió se basó en los conceptos de la arquitectura de negocio y en la estructura propuesta por Kale (2019). Este trabajo se divide en tres grandes partes: la primera, denominada situación actual, comprende el entendimiento del contexto de negocio del sector turístico. Dado que la principal impulsora de las transformaciones sectoriales es la generación de mercados que fomenten las iniciativas empresariales, en esta parte se identificaron la posición del sector en el mundo, el modelo de negocio, las fuentes de financiamiento y los indicadores objetivos que busca la estrategia de desarrollo; también se analizó la comprensión de la legislación vigente en Colombia, dada la política de Gobierno que se desea promover, y se llevó a cabo un diagnóstico externo en el que se tuvo en cuenta a la comunidad de la región objeto de estudio.

En la segunda sección, llamada estrategias de transformación digital, se determinaron los motivadores de negocio fuertes que sustentan esta transformación y se diseñó un mapa de brecha en el que se reconocieron las diferencias entre el estado actual y aquel deseado según las metas del plan estratégico; cada una de estas brechas fueron agrupadas en cinco estrategias de transformación según su temática, y cada temática fue representada gráficamente con la imagen de un ave representativa de Colombia, dado el potencial que tiene el país en avistamiento de aves (Quiñones, 2019). Para cada una de las estrategias de transformación, se generó una ficha técnica que contiene su correspondiente descripción junto con sus iniciativas codificadas para una posterior programación en el cronograma de implementación.

En la tercera parte, implementación de la estrategia, se elaboró un prototipo funcional con el fin de que los tomadores de decisiones pudieran visualizar una vista previa de la materialización de la estrategia. Además, se generó una arquitectura de solución con el objetivo de poder proyectar técnicamente el desarrollo de software detrás de la solución planteada.

Esta metodología pretende funcionar como un paso a paso para que otras entidades o países puedan plantear la transformación digital de sus sectores económicos de la mano de los gobiernos, con la finalidad de materializar sus objetivos. En este caso se trabajó sobre el sector turístico, pero puede llegar a utilizarse en diversidad de escenarios de implementación de política pública.

\section{Situación actual}

Se mostrará a continuación un diagnóstico condensado de las principales vistas del sector turístico en Colombia, en general, y en Boyacá, en particular, con el objetivo de identificar las estructuras de negocio que conducirán todo el proceso de transformación digital. 


\subsection{Tranformación digital desde el negocio}

Actualmente, en el Plan Sectorial de Turismo (Mincit, 2019) se plantea la transformación digital del sector con el fin de cumplir los objetivos estratégicos propuestos, además de ser un propósito de la Ley del Plan Nacional de Desarrollo, como se indica en los artículos 92, 93 y 230 (DNP, 2019). Al respecto, se mostrará a continuación un análisis de la situación actual tanto de Colombia, en general, como del caso específico de estudio: Boyacá. Este énfasis en entender en profundidad el negocio es muy importante, dado que el negocio será el principal impulsor de estas transformaciones, que han sido propuestas en línea con el cumplimiento de los Objetivos de Desarrollo Sostenible de las Naciones Unidas (UN, s. f.), de acuerdo con la manera como lo plantea la Organización Mundial del Turismo (OMT) (UNWTO, s. f.).

\subsubsection{Turismo en el mundo}

La Organización Mundial del Turismo (OMT) emite cada año las cifras correspondientes a los países que repuntan en este sector. Se exponen a continuación, en la figura 1 , las cifras de crecimiento general del turismo en el año 2018, agrupadas por continentes.

De acuerdo con la OMT, el crecimiento en las Américas fue del $2 \%$. Este porcentaje es bajo comparado con otros mercados, como el asiático, con incrementos cercanos al $7 \%$, lo que acentúa la necesidad de Colombia de crecer a una mayor velocidad si quiere ser un líder en la región en cuanto a la generación de riqueza basada en el turismo.

En Latinoamérica, Colombia ocupa el séptimo puesto en número de visitantes extranjeros (WTO, 2019), lo que representa una fuerte presión para ser un líder en el

Figura 1. Crecimiento del turismo en 2018

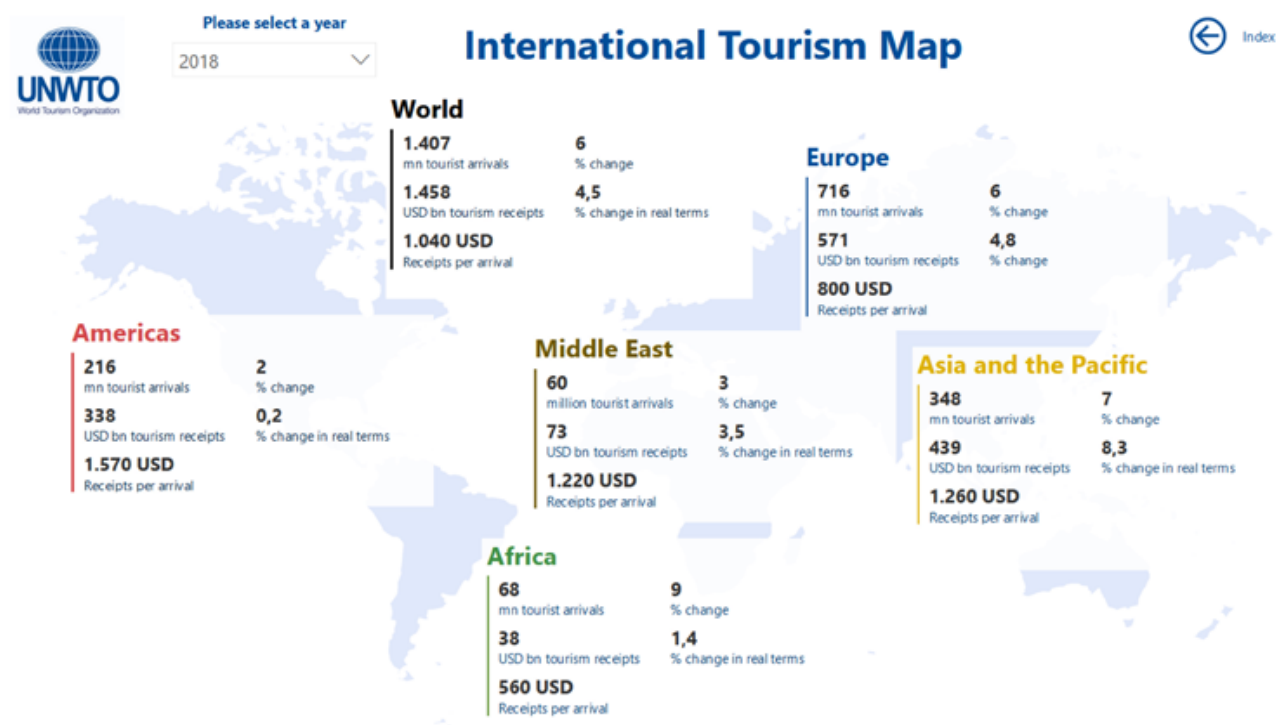

Fuente: WTO (2019). 
Tabla 1. Países más visitados en 2018

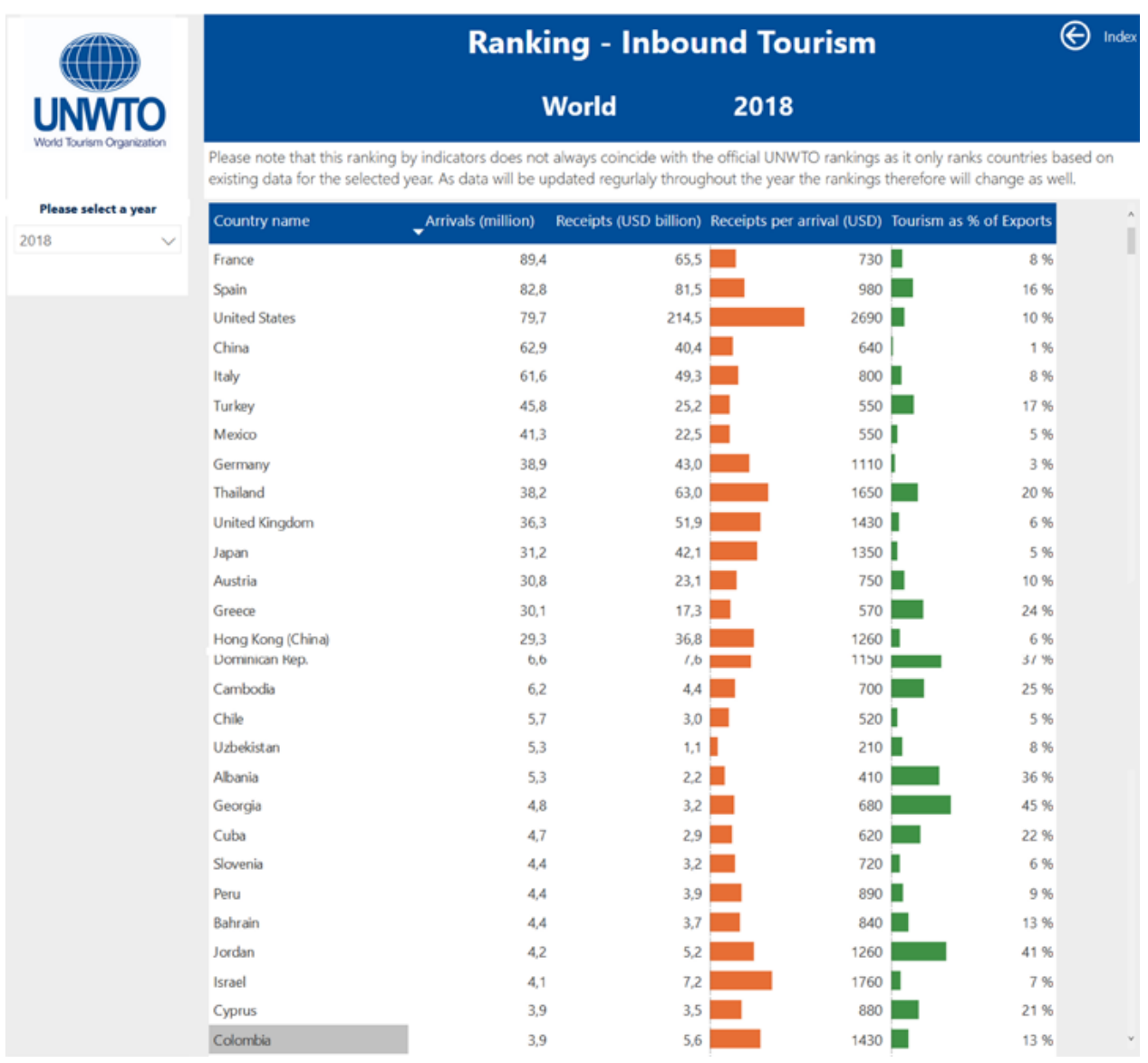

Fuente: WTO (2019).

mercado; además, se encuentra muy cerca de sus competidores más inmediatos: Perú, Cuba, Puerto Rico y Uruguay. Es por esto por lo que Colombia requiere generar ventajas competitivas sólidas sobre sus rivales, dado que la oferta de servicios puede llegar a ser muy similar con respecto al resto de la región.

Tabla 2. Países más visitados en Latinoamérica en 2018

\begin{tabular}{|c|c|c|}
\hline Posición & País & Millones de turistas \\
\hline $1 .^{\circ}$ & México & 41,3 \\
\hline $2 .^{\circ}$ & Argentina & 6,7 \\
\hline
\end{tabular}

\begin{tabular}{|c|c|c|}
\hline Posición & País & Millones de turistas \\
\hline $3 .^{\circ}$ & Brasil & 6,6 \\
\hline $4 .^{\circ}$ & Chile & 6,4 \\
\hline $5 .^{\circ}$ & $\begin{array}{c}\text { República } \\
\text { Dominicana }\end{array}$ & 6,4 \\
\hline $6 .^{\circ}$ & Perú & 4,1 \\
\hline $7 .^{\circ}$ & Colombia & 3,9 \\
\hline $8 .^{\circ}$ & Cuba & 3,9 \\
\hline $9 .^{\circ}$ & Puerto Rico & 3,8 \\
\hline $10 .^{\circ}$ & Uruguay & 3,7 \\
\hline
\end{tabular}

Fuente: WTO (2019). 


\subsubsection{Turismo en Colombia}

Colombia es un país turísticamente importante debido a que año tras año alberga a millones de extranjeros, quienes son atraídos por sus playas, patrimonio artístico, cultura, gastronomía y por ser uno de los países de América más ricos en patrimonio cultural.

En Colombia, la regulación del turismo es una de las funciones del Ministerio de Comercio, Industria y Turismo (MincIT), a veces con el asocio de los Ministerios de Cultura y Hacienda en la implementación de políticas públicas para promover la economía del país y la generación de empleo para la sociedad colombiana (GSD, 2013).

La mayoría de los turistas extranjeros que visitan Colombia provienen de países vecinos de Latinoamérica y del Caribe, de América del Norte y Europa. Según cifras del MinciT (CITUR, 2019), el número de visitantes extranjeros que hicieron su registro al país en 2018 por las vías marítima y terrestre fue de 4.338.816, de los cuales el $81,77 \%$ se desplazaron por motivo de vacaciones, recreo y ocio; el 10,74 \% lo hicieron por negocios y razones profesionales; el 1,75\%, por educación y formación; y el 5,74\% arribaron por otras causas (salud, religión, tránsito, visitas a familiares, etc.).

El Gobierno nacional hizo un balance del sector turismo en Colombia en los últimos años (2010-2018) (Revista Dinero, 2018); en él se destacó el positivo desempeño que este rubro económico ha tenido, en especial después del Acuerdo de Paz con las Farc. El MinciT expuso que el aumento de visitantes extranjeros al país fue del $150 \%$ en esos 8 años.

Estos son los datos más relevantes del sector turismo entre 2010 y 2018 :
1. Entre 2010 y 2017 , el ingreso de divisas por turismo creció un $68,2 \%$.

2. La inversión en los hoteles en el país fue de $\$ 5,7$ billones (2003 y 2017).

3. El aporte del turismo al PIB en 2018 fue del $6,9 \%$, mientras que en 2017 fue del $1,6 \%$.

4. Se crearon 1,9 millones de empleos formales en este sector.

5. Se implementaron 45 rutas turísticas (30 geográficas y 15 temáticas) en 32 departamentos.

En cuanto a la utilización de tecnologías de la información, es muy común que los visitantes hagan uso de buscadores de alojamiento con ofertas para disfrutar su estadía. También existen aplicaciones que facilitan el viaje a los turistas, como es el caso de Colombia Travel App (Colombia Travel, 2019) o de Colombia Map (CityApp, 2019), que ofrecen al turista información de las diferentes ciudades del país y sobre aquellos sitios más turísticos. Estas aplicaciones no se centran en la experiencia del usuario ni muestran la información almacenada y verificada, como sí lo hace el Registro Nacional de Turismo (RNT), el cual le da plena certeza al turista de que el servicio prestado es legal y tiene un conducto regulado para garantizar la calidad del servicio.

\subsubsection{Turismo regional. Caso \\ de estudio: Boyacá}

En 2017, el departamento de Boyacá contaba con 11.362 habitaciones en alojamientos turísticos, un 36,81\% de ocupación y un flujo de turismo receptor de 6.991 turistas. En 2018, ese flujo bajó a 6.242 turistas, lo cual significa un decrecimiento de $-11 \%$. Las cifras evidencian una fuerte caída de los 
Figura 2. Comparación de porcentaje de ocupación hotelera de Boyacá vs. Colombia

60

50
40
30
20
10
0

50
40
30
20
10
0

50
40
30
20
10

0

50
40
30
20
10
0

50
40
30
20
10
0

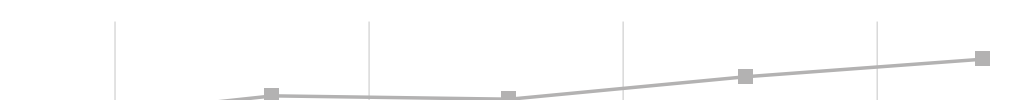

Fuente: CITUR (2019).

indicadores de empleabilidad en el sector turístico en el departamento desde enero de 2018, con un leve repunte en agosto de ese mismo año (SITUR, 2018).

Además, los indicadores de ocupación hotelera predominantemente han estado por debajo de la media nacional en los últimos años, en los que se puede analizar que existe un potencial de mercado, pero que no está siendo cautivado por la industria turística del departamento.

En un estudio de diagnóstico patrocinado por Colciencias en el Plan Estratégico Departamental de Ciencia, Tecnología e Innovación (Observatorio Colombiano de Ciencia y Tecnología, 2012) y en el Plan de Desarrollo Turístico Sostenible del Departamento de Boyacá (FONTUR, 2012) se identificaron fuertes falencias con respecto a la implementación de tecnologías de la información en el departamento de Boyacá.

Respecto a las bajas cifras del turismo en el departamento, no se identifica una estrategia digital que sirva de impulso al sector en el área tecnológica y que haya dado frutos,

solo se cuenta con iniciativas aisladas, fundamentalmente materializadas en aplicaciones o páginas web de turismo que proveen contenido. Entre las aplicaciones disponibles en la plataforma Google Play se encuentran las siguientes:

- BiciBoyacá, publicitada como aplicación oficial de la Gobernación de Boyacá, sin embargo, en el sitio oficial de la Gobernación no se encuentra referencia a esta aplicación. BiciBoyacá promueve el turismo mediante la publicación de rutas ciclísticas y aspectos asociados con el ciclismo recreativo.

- Boyacá sobre Ruedas ofrece información acerca de rutas de transporte público y tarifas.

- Turismo Boyacá, aplicación con información turística enfocada en 30 municipios de los 123 que componen el departamento. La información presentada a los usuarios proviene de las fuentes oficiales de la Secretaría de Turismo del departamento. 
- Boyacá en 360 ofrece vistas de $360^{\circ}$ de algunos de los atractivos turísticos del departamento.

Sitios web:

- Boyacá Turismo (http://www.boyacaturismo.com), agencia de viajes que ofrece paquetes turísticos, pero sin posibilidad de compras en línea.
- Crucero Turismo (https://www.cruceroturismo.net), agencia de viajes con la posibilidad de pagos en línea.

- Situr Boyacá (https://www.situr.boyaca. gov.co).

No se evidencia otro tipo de iniciativas digitales de impacto en el sector turístico con tecnologías como IoT, realidad aumentada,

Tabla 3. Marco jurídico del turismo

\begin{tabular}{|c|c|}
\hline Normativa & Descripción \\
\hline $\begin{array}{l}\text { Constitución Política de } \\
\text { Colombia de } 1991\end{array}$ & $\begin{array}{l}\text { Ejerce la potestad reglamentaria mediante la expedición de los decretos, las resoluciones } \\
\text { y órdenes necesarios para la cumplida ejecución de las leyes. }\end{array}$ \\
\hline Ley 300 de 1996 & Por la cual se expide la Ley General de Turismo y se dictan otras disposiciones. \\
\hline Ley 527 de 1999 & $\begin{array}{l}\text { Por medio de la cual se define y reglamenta el acceso y uso de los mensajes de datos, del } \\
\text { comercio electrónico y de las firmas digitales, se establecen las entidades de certifica- } \\
\text { ción y se dictan otras disposiciones. }\end{array}$ \\
\hline Ley 1101 de 2006 & $\begin{array}{l}\text { Por medio de esta ley se modifica la Ley } 300 \text { de } 1996 \text { (Ley General de Turismo) y se } \\
\text { dictan otras disposiciones. }\end{array}$ \\
\hline Ley 1266 de 2008 & Disposiciones generales de habeas data y regulación del manejo de la información. \\
\hline Decreto 235 de 2010 & Intercambio de información entre entidades para el cumplimiento de funciones públicas. \\
\hline Decreto 019 de 2012 & Decreto antitrámites, por medio del cual se mejora la relación Estado-ciudadano. \\
\hline Decreto 2364 de 2012 & Decreto Reglamentario de Firma Electrónica. \\
\hline Ley 1558 de 2012 & $\begin{array}{l}\text { Por la cual se modifican la Ley } 300 \text { de } 1996 \text { (Ley General de Turismo) y la Ley } 1101 \text { de } \\
\text { 2006, y se dictan otras disposiciones. }\end{array}$ \\
\hline Ley 1581 de 2012 & Por la cual se dictan disposiciones generales para la protección de datos personales. \\
\hline NTC 5854 de 2012 & Norma técnica de accesibilidad a páginas web. \\
\hline Decreto 1377 de 2013 & Por el cual se reglamenta parcialmente la Ley 1581 de 2012. \\
\hline Decreto 886 de 2014 & $\begin{array}{l}\text { Por el cual se reglamenta el artículo } 25 \text { de la Ley } 1581 \text { de 2012, relativo al Registro } \\
\text { Nacional de Bases de Datos. }\end{array}$ \\
\hline Ley 1712 de 2014 & Ley de Transparencia y del Derecho de Acceso a la Información Pública Nacional. \\
\hline Decreto 1074 de 2015 & $\begin{array}{l}\text { Decreto Único Reglamentario del Sector Comercio, Industria y Turismo, mediante el } \\
\text { cual se reglamenta la información mínima que debe contener el RNBD. }\end{array}$ \\
\hline Decreto 1078 de 2015 & Decreto Único Sectorial-Lineamientos Generales de Gobierno en Línea. \\
\hline $\begin{array}{l}\text { Resolución } 3564 \text { de } \\
2015\end{array}$ & $\begin{array}{l}\text { Reglamentaciones asociadas con la Ley de Transparencia y Acceso a la Información } \\
\text { Pública. }\end{array}$ \\
\hline $\begin{array}{l}\text { Resolución } 3860 \text { de } \\
2015\end{array}$ & $\begin{array}{l}\text { Reglamentación de la Norma Técnica Sectorial de Turismo de Aventura y Sostenibilidad } \\
\text { Turística (certificacioncalidadturistica.com.co). }\end{array}$ \\
\hline
\end{tabular}




\begin{tabular}{|c|c|}
\hline Normativa & Descripción \\
\hline Decreto 415 de 2016 & $\begin{array}{l}\text { Lineamientos para el fortalecimiento institucional en materia de tecnologías de la infor- } \\
\text { mación y las comunicaciones. }\end{array}$ \\
\hline Circular 3 de 2016 & $\begin{array}{l}\text { Las agencias de viajes deben contratar o intermediar la prestación de servicios turísticos } \\
\text { en Colombia con empresas que cumplan sus obligaciones frente al Registro Nacional de } \\
\text { Turismo. }\end{array}$ \\
\hline Decreto 229 de 2017 & $\begin{array}{l}\text { Se reglamenta la prestación del servicio de alojamiento turístico y se determina el soft- } \\
\text { ware para administración de tarjeta de registro hotelero. }\end{array}$ \\
\hline Decreto 2063 de 2018 & Actualización normativa de la inscripción al Registro Nacional de Turismo. \\
\hline Decreto 2119 de 2018 & Se reglamenta la prestación del servicio de alojamiento turístico. \\
\hline Decreto 90 de 2018 & $\begin{array}{l}\text { Por el cual se modifican los artículos 2.2.2.26.1.2 y 2.2.2.26.3.1 del Decreto } 1074 \text { de } \\
2015 \text { (Decreto Único Reglamentario del Sector Comercio, Industria y Turismo). }\end{array}$ \\
\hline Ley 1943 de 2018 & $\begin{array}{l}\text { Ley de Financiamiento, por la que se generan beneficios tributarios para economía } \\
\text { naranja. }\end{array}$ \\
\hline Ley 1955 de 2019 & Plan Nacional de Desarrollo 2018-2022. \\
\hline Decreto 297 de 2016 & $\begin{array}{l}\text { Se reglamenta la exención del impuesto sobre las ventas (IVA) para los servicios turísti- } \\
\text { cos, establecida en el literal d) del artículo } 481 \text { del Estatuto Tributario, modificado por el } \\
\text { artículo } 55 \text { de la Ley } 1607 \text { de } 2012 \text {. }\end{array}$ \\
\hline Decreto 431 de 2017 & Prestación del servicio público de transporte terrestre automotor especial. \\
\hline Ley 2010 de 2019 & $\begin{array}{l}\text { Por la cual se adoptan normas para la promoción del crecimiento económico, el empleo, } \\
\text { la inversión, el fortalecimiento de las finanzas públicas y la progresividad, equidad y } \\
\text { eficiencia del sistema tributario. }\end{array}$ \\
\hline
\end{tabular}

Fuente: Elaboración propia.

inteligencia de negocios analítica predictiva, etc., que fortalezcan el sector y apalanquen el mejoramiento de los indicadores.

\subsubsection{Marco jurídico colombiano}

En la tabla 3 se exponen las principales normas legales sobre turismo en Colombia, en las que se enmarcan los temas tratados en este trabajo y que los afectan de manera directa o indirecta, dado que el ordenamiento jurídico colombiano es el marco de acción del Ejecutivo dentro de la ley.

\subsubsection{Definición del problema}

Debido a los cambios actuales surgidos por las tecnologías de la información y las comunicaciones (TIC) en la forma como los ciudadanos interactúan, se identificó la necesidad de proveer a los diferentes actores de herramientas útiles para la interacción con el Gobierno, con el fin de que estos instrumentos ayuden a cumplir los objetivos estratégicos propuestos en el Plan Nacional de Desarrollo 2018-2022. Puesto que una de las prioridades del Gobierno nacional es la generación de prosperidad por medio del turismo y de una economía cada vez más digital, se identificó la oportunidad de darle valor a la información que posee el Viceministerio de Turismo (entidad del Gobierno de Colombia encargada de la gestión del sector) con el Registro Nacional de Turismo (RNT), los inventarios y corredores turísticos, además de resolver otros grandes retos que afronta el sector para potenciarse. 


\subsection{Diagnóstico interno}

Este diagnóstico estará comprendido por un análisis interno entre el sector turístico y el Viceministerio de Turismo, con el fin de comprender el negocio desde la estructura institucional de la entidad.

\subsubsection{Modelo de negocio}

Este modelo de negocio comprende la estructura general de la venta de productos y servicios turísticos en el país.

\subsubsection{Clientes}

El Viceministerio de Turismo cuenta con un conjunto variado de clientes que utilizan los servicios ofrecidos básicamente con un objetivo de desarrollo social y económico para la nación. En la tabla 5 se describen los clientes en detalle.

\subsubsection{Canales de distribución}

De la misma forma en que los clientes son variados, se pueden determinar uno o varios canales de distribución, que se resumen en los siguientes tipos:

- Canales de promoción, por los cuales se divulgan a la población nacional e internacional los destinos, las rutas, los atractivos y, en general, toda la promoción turística del país.

- Canales de atención al ciudadano, aquellos canales de soporte a los servicios ofrecidos por el Viceministerio, ya sea para la gestión de nuevas solicitudes o para la radicación y el seguimiento de PQRS.

- Canales de creación y divulgación de política pública, canales de generación y consolidación de propuestas para el

Tabla 4. Canvas de modelo de negocio

\begin{tabular}{|c|c|c|c|c|}
\hline Relaciones clave & Actividades clave & Propuesta de valor & Relación con clientes & $\begin{array}{l}\text { Seguimiento de } \\
\text { clientes }\end{array}$ \\
\hline \multirow{3}{*}{$\begin{array}{l}\text { - } \text { Proveedores } \\
\text { - Agremiaciones } \\
\text { - Cooperación } \\
\text { internacional } \\
\text { - Otros ministe- } \\
\text { rios }\end{array}$} & $\begin{array}{l}\text { - Definición de políti- } \\
\text { cas } \\
\text { - Promoción } \\
\text { - Medición y control } \\
\text { - Gestión turística }\end{array}$ & \multirow{3}{*}{$\begin{array}{l}\text { Generar un entorno } \\
\text { confiable y seguro } \\
\text { para la promoción, } \\
\text { la presentación y el } \\
\text { consumo de servicios } \\
\text { turísticos por medio } \\
\text { de la política pública, } \\
\text { que tiendan a mejo- } \\
\text { rar la competitividad } \\
\text { y la sostenibilidad. }\end{array}$} & $\begin{array}{l}\text { - } \text { Comunicación de } \\
\text { prensa } \\
\text { - } \text { Comunicación } \\
\text { oficial } \\
\text { - Ferias y congresos } \\
\text { - Acercamiento a } \\
\text { líderes gremiales }\end{array}$ & \multirow{3}{*}{$\begin{array}{l}\text { - Ciudadanos } \\
\text { colombianos } \\
\text { - Ciudadanos } \\
\text { extranjeros } \\
\text { - Prestadores de } \\
\text { servicios turísticos }\end{array}$} \\
\hline & Recursos clave & & Canales de distribución & \\
\hline & $\begin{array}{l}\text { - Registro Nacional } \\
\text { de Turismo (RNT) } \\
\text { - Inventarios turísti- } \\
\text { cos } \\
\text { - Tecnologías de la } \\
\text { información }\end{array}$ & & $\begin{array}{l}\text { - Canales de promo- } \\
\text { ción } \\
\text { - Canal de atención al } \\
\text { ciudadano } \\
\text { - Canal de creación } \\
\text { y distribución de } \\
\text { política pública }\end{array}$ & \\
\hline \multicolumn{2}{|r|}{ Estructura de costos } & \multicolumn{3}{|c|}{ Flujo de ingresos } \\
\hline \multicolumn{2}{|c|}{$\begin{array}{l}\text { - Costo de proyectos } \\
\text { - Costo de proveedores } \\
\text { - Nómina de empleados públicos }\end{array}$} & \multicolumn{3}{|c|}{$\begin{array}{l}\text { - Fondo Nacional de Turismo (FONTUR) } \\
\text { - Sistema General de Regalías } \\
\text { - Presupuesto General de la Nación }\end{array}$} \\
\hline
\end{tabular}

Fuente: Elaboración propia. 
Tabla 5. Identificación de interesados

\begin{tabular}{|c|c|c|c|}
\hline$I D$ & Nombre & Tipos & Descripción \\
\hline CL01 & Funcionarios & $\begin{array}{l}\text { Nacionales } \\
\text { Departamentales } \\
\text { Regionales }\end{array}$ & $\begin{array}{l}\text { Personas al servicio de entidades gubernamentales de } \\
\text { índole territorial que son recursos activos en el sector } \\
\text { turístico. }\end{array}$ \\
\hline CL02 & $\begin{array}{l}\text { Prestadores } \\
\text { de servicios }\end{array}$ & $\begin{array}{l}\text { De hospedaje } \\
\text { De actividades }\end{array}$ & $\begin{array}{l}\text { Personas naturales o jurídicas que suministran servicios al } \\
\text { público y cumplen con todas las normas de funcionamien- } \\
\text { to y seguridad. }\end{array}$ \\
\hline CL03 & Ciudadanos & $\begin{array}{l}\text { Nacionales } \\
\text { Extranjeros }\end{array}$ & $\begin{array}{l}\text { Viajeros dentro del territorio colombiano que requieren } \\
\text { servicios turísticos confiables. }\end{array}$ \\
\hline CL04 & Autoridades & $\begin{array}{l}\text { Fuerza pública } \\
\text { Ministerios } \\
\text { Superintendencia de Industria } \\
\text { y Comercio } \\
\text { Corporaciones regionales }\end{array}$ & $\begin{array}{l}\text { Entidades de control que velan por la aplicación de las } \\
\text { normas y por el correcto funcionamiento de los prestado- } \\
\text { res y la defensa de los usuarios de servicios de turismo en } \\
\text { Colombia. }\end{array}$ \\
\hline CL05 & $\begin{array}{l}\text { Comunidad } \\
\text { internacional }\end{array}$ & $\begin{array}{l}\text { OCDE } \\
\text { Organización Mundial de } \\
\text { Turismo } \\
\text { Alianza del Pacífico } \\
\text { Cooperación internacional }\end{array}$ & $\begin{array}{l}\text { Organizaciones internacionales que brindan pautas para } \\
\text { aplicar estándares en el sector turístico colombiano. Tam- } \\
\text { bién apoyan económicamente los proyectos turísticos. }\end{array}$ \\
\hline
\end{tabular}

Fuente: Elaboración propia.

fortalecimiento de políticas públicas relacionadas con el sector turismo en Colombia.

\subsubsection{Relacionamiento con el cliente}

El relacionamiento con los clientes del Viceministerio de Turismo actualmente se resume en cinco medios oficiales: 1) comunicados de prensa, 2) comunicados oficiales, 3) ferias y congresos, 4) Talleres Construyendo País y 5) reuniones con líderes gremiales.

\subsubsection{Fuentes de ingresos}

Por tratarse de una entidad gubernamental, los ingresos del Viceministerio de Turismo provienen básicamente de tres fuentes: FONTUR (Fondo Parafiscal de Turismo), Sistema General de Regalías y Presupuesto General de la Nación.

\subsubsection{Cadena de valor del sector turístico}

Este modelo de la cadena de valor actual del sector turismo fue tomado de un informe para la estrategia del turismo en Colombia presentado por McKinsey \& Co al Fondo Nacional de Turismo (FONTUR) (McKinsey \& Co, 2012).

Se habla de una cadena de valor dinámica o multicanal, ya que el consumidor de servicios de turismo cuenta con múltiples vías de acceso a cualquier destino.

Figura 3. Cadena de valor del sector turístico

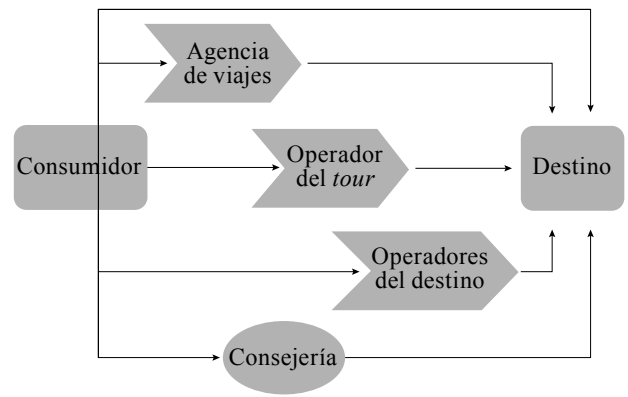

Fuente: McKinsey \& Co (2012).

- Las agencias de viajes han comenzado a hacer reservas de manera directa, sin pasar por los operadores de tour $\mathrm{u}$ 
operadores de destino (que tradicionalmente eran el único canal directo con el cliente).

- Debido a la creciente competencia, los operadores de tour se han convertido en jugadores especializados en nichos y se enfocan particularmente en geografías y segmentos de consumidores.

- Los operadores de destino han comenzado a competir por ser el primer punto de contacto, pues prometen ofertas a la medida y especializadas. Algunas empresas han empezado a invertir en activos turísticos (p. ej.: hoteles safari).

- Los servicios de consejería han entrado a la cadena de valor de lujo y se han vuelto consejeros de viaje de ricos y famosos. Ellos proveen al segmento de súper lujo, impulsado por el "voz a voz", y negocian directamente con los destinos.

\subsubsection{Definición}

de escenarios de negocio

El problema se abordó desde la óptica de la utilización de la información disponible que no estaba generando el valor potencial que tiene. Aquí el Registro Nacional de Turismo (RNT) representa la legalidad del sector privado, que aporta a la mejora del sector turístico. El soporte del RNT lo conforman los datos de los inventarios turísticos (que son todos los atractivos con los que el país cuenta para ofrecer en sus diferentes regiones y que son un potencial atractivo para los turistas), además de los corredores turísticos que agrupan estos inventarios a lo largo de un recorrido de ciudades que presentan intereses similares y que dan un entorno de valor al turista.

Debido al gran tamaño y a la variedad de todo el territorio colombiano, se tomó como caso de estudio el departamento de Boyacá, dado que es representativo de todo el país, pues tiene variedad de climas, una oferta turística variada, potencial económico sin ejecutar, atractivos de talla mundial y un tamaño similar con respecto a otros departamentos. Todo esto hace de Boyacá un caso replicable para otras regiones del país en donde este plan se pudiera ejecutar.

Se tomaron como visión estratégica el nuevo Plan Nacional de Desarrollo 2018-2022 (DNP, 2018) y el Plan Sectorial de Turismo 2018-2022 (Mincit 2019), debido a que son las hojas de ruta en la implementación de la política pública a lo largo de los próximos tres años y representan los objetivos propuestos que se desea alcanzar como nación para mejorar el nivel de vida de todos los colombianos.

\subsubsection{Modelo financiero}

En el año 2018 se aprobaron \$105.491 millones, representados en 170 aprobaciones entre proyectos y adiciones; estas aprobaciones se reflejan en la figura 4, discriminadas por regiones y agrupadas en tres frentes: competitividad, infraestructura y promoción.

Las asignaciones totales por región se indican en la tabla 6.

Tabla 6. Asignación de recursos por regiones de Colombia

\begin{tabular}{|l|c|c|}
\hline \multicolumn{1}{|c|}{ Región } & Participación & Monto \\
\hline Andina & $18 \%$ & $\$ 19.077$ \\
\hline Caribe e Insular & $9 \%$ & $\$ 9.013$ \\
\hline Pacífica & $9 \%$ & $\$ 9.415$ \\
\hline Amazonía & $7 \%$ & $\$ 7.831$ \\
\hline Orinoquía & $4 \%$ & $\$ 3.784$ \\
\hline Nacional & $53 \%$ & $\$ 56.371$ \\
\hline
\end{tabular}

Fuente: FONTUR (2019).

Para el departamento de Boyacá, las aprobaciones corresponden a $\$ 1.100$ millones. 
Figura 4. Aprobaciones 2018 por regiones

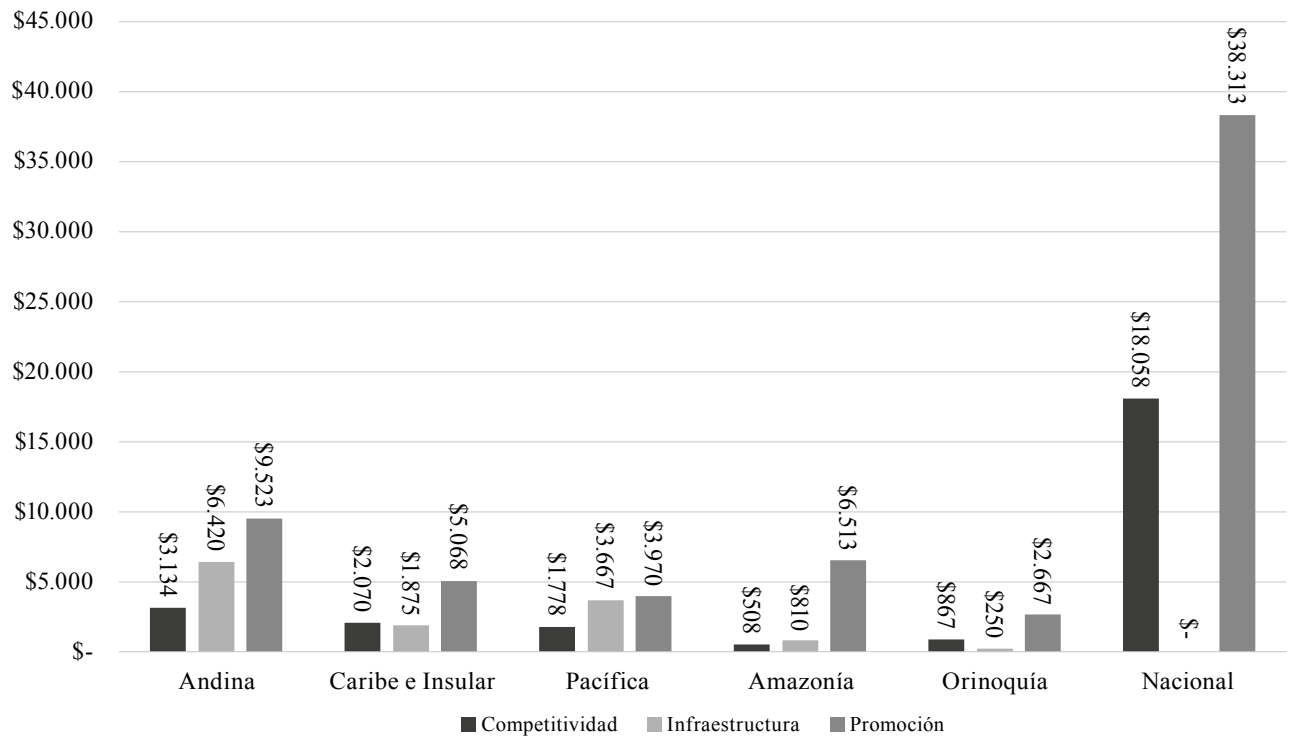

Fuente: FONTUR (2019).

Figura 5. Destinación de la apropiación de recursos a Boyacá Aprobaciones Boyacá 2018

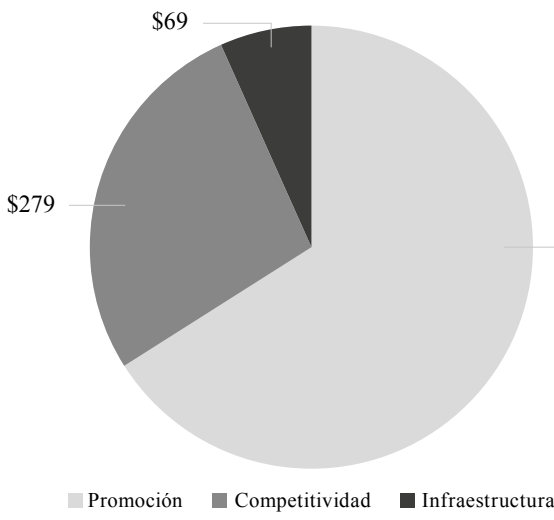

Fuente: FONTUR (2019)

\subsubsection{Modelo estratégico}

Se diseñó un esquema de los indicadores clave en el que se identifican los principios de la visión y la misión; el esquema se enfoca en las prioridades y estrategias identificadas y en las perspectivas de los indicadores, con su respectiva comparación. Se generó una relación entre los indicadores clave y aquellos propuestos por la Organización para la Cooperación y el Desarrollo Económico (OCDE), los cuales se explicarán en el modelo de información a continuación.

\subsubsection{Modelo de información}

Los indicadores definidos se basan en los propuestos por la Organización para la Cooperación y el Desarrollo Económico (OCDE), de la cual el Gobierno de Colombia forma parte luego de firmar un acuerdo de adhesión en 2018 (OECD, 2018). Es por esto por lo que se tomaron como indicadores claves de medición aquellos de turismo contenidos en el documento Indicators for measuring competitiveness in tourism: A guidance document (Dupeyras y MacCallum, 2013), con el fin de generar indicadores que sean comparables con los de los países miembros de la OCDE. Y para el presente trabajo se seleccionaron algunos de los indicadores propuestos de acuerdo con la alineación con la estrategia y la visión definidas en el Plan Nacional de Desarrollo 2018-2022 (DNP, 2019) y el Plan Sectorial de Turismo 2018-2022 (Mincit, 2019). 
Tabla 7. Cuadro de mando integrado por indicadores

\begin{tabular}{|l|l|l|l|}
\hline Visión & \multicolumn{2}{|l|}{$\begin{array}{l}\text { Para el año 2022, el Mincit coadyuvará con la generación de políticas, articulará los sectores de } \\
\text { manera eficaz, con un enfoque innovador y tecnológico, y facilitará la participación y colaboración } \\
\text { de los ciudadanos. }\end{array}$} \\
\hline Misión & $\begin{array}{l}\text { Acordar, ejecutar y evaluar la política turística, así como los planes y programas derivados de esta, } \\
\text { en conjunto con las entidades competentes de los sectores público y privado, con el fin de mejorar } \\
\text { la competitividad y sostenibilidad de los productos y destinos turísticos y promover el turismo } \\
\text { doméstico y receptivo. }\end{array}$ \\
\hline $\begin{array}{l}\text { Prioridades } \\
\text { estratégicas }\end{array}$ & $\begin{array}{l}\text { Promover a nivel nacional e } \\
\text { internacional la visita a destinos } \\
\text { turísticos colombianos. }\end{array}$ & $\begin{array}{l}\text { Generar prosperidad econó- } \\
\text { mica, social y ambiental para } \\
\text { todos los colombianos. }\end{array}$ & $\begin{array}{l}\text { Impulsar la creación de em- } \\
\text { presas de vocación turística } \\
\text { y respetuosas de la ley en } \\
\text { Colombia. }\end{array}$ \\
\hline $\begin{array}{l}\text { Resultado } \\
\text { estratégico }\end{array}$ & $\begin{array}{l}\text { Posicionar a Colombia como un } \\
\text { referente de turismo. }\end{array}$ & $\begin{array}{l}\text { Mejorar el nivel de vida de } \\
\text { todos los colombianos a partir } \\
\text { del trabajo y la preserva- } \\
\text { ción del medioambiente. }\end{array}$ & $\begin{array}{l}\text { Aumentar el número de empre- } \\
\text { sas legales que contribuyen con } \\
\text { el país y en la generación de } \\
\text { empleo formal y de calidad. }\end{array}$ \\
\hline
\end{tabular}

\begin{tabular}{|c|c|c|c|c|c|c|c|}
\hline Perspectiva & Código & $O C D E$ & $\begin{array}{l}\text { Descripción del } \\
\text { indicador }\end{array}$ & Medición & Actual & Objetivo & Brecha \\
\hline \multirow{3}{*}{ 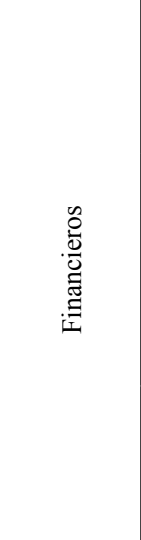 } & GOAL_01 & KPI-02 & $\begin{array}{l}\text { Divisas producidas } \\
\text { por la llegada de turis- } \\
\text { tas extranjeros }\end{array}$ & $\begin{array}{l}\text { Millones de dólares } \\
\text { por turismo calcula- } \\
\text { dos por el Banco de la } \\
\text { República }\end{array}$ & 5.801 & 8.000 & $38 \%$ \\
\hline & GOAL_02 & KPI-01 & $\begin{array}{l}\text { Producto interno } \\
\text { bruto (PIB) en aloja- } \\
\text { miento y servicios de } \\
\text { comida }\end{array}$ & $\begin{array}{l}\text { Miles de millones de } \\
\text { pesos, series enca- } \\
\text { denadas de volumen } \\
\text { con año de referencia } \\
2015 \text {, medidos por el } \\
\text { DANE }\end{array}$ & 31.698 & 39.121 & $23 \%$ \\
\hline & GOAL_03 & & $\begin{array}{l}\text { Inversión extranjera } \\
\text { directa acumulada en } \\
\text { millones de dólares }\end{array}$ & $\begin{array}{l}\text { Millones de dólares } \\
\text { por turismo calcula- } \\
\text { dos por el Banco de la } \\
\text { República }\end{array}$ & 890 & 2.000 & $125 \%$ \\
\hline \multirow{3}{*}{ 节 } & GOAL_04 & KPI-7 & $\begin{array}{l}\text { Número de empleos } \\
\text { directos generados } \\
\text { por turismo }\end{array}$ & $\begin{array}{l}\text { Número de empleos } \\
\text { directos por turismo } \\
\text { calculado por el DANE }\end{array}$ & 888.675 & 1.158 .391 & $30 \%$ \\
\hline & GOAL_05 & KPI-7 & $\begin{array}{l}\text { Número de empleos } \\
\text { indirectos generados } \\
\text { por turismo }\end{array}$ & $\begin{array}{l}\text { Número de empleos } \\
\text { indirectos por turismo } \\
\text { calculado por el DANE }\end{array}$ & 1.014 .269 & 1.215 .361 & $20 \%$ \\
\hline & GOAL_06 & & $\begin{array}{l}\text { Número de prestado- } \\
\text { res de servicios turís- } \\
\text { ticos certificados }\end{array}$ & $\begin{array}{l}\text { Número de prestado- } \\
\text { res cuyo certificado se } \\
\text { encuentre registrado } \\
\text { en turismocolombia. } \\
\text { gov.co }\end{array}$ & 1.074 & 2.500 & $133 \%$ \\
\hline
\end{tabular}




\begin{tabular}{|c|c|c|c|c|c|c|c|}
\hline Perspectiva & Código & $O C D E$ & $\begin{array}{l}\text { Descripción del } \\
\text { indicador }\end{array}$ & Medición & Actual & Objetivo & Brecha \\
\hline \multirow[t]{2}{*}{ 莺 } & GOAL_07 & KPI-8 & $\begin{array}{l}\text { Índice de precios al } \\
\text { consumidor para el } \\
\text { turismo }\end{array}$ & $\begin{array}{l}\text { Promedio ponde- } \\
\text { rado normalizado } \\
\text { de precios para una } \\
\text { determinada clase de } \\
\text { bienes o servicios en } \\
\text { una región específica } \\
\text { durante un intervalo } \\
\text { de tiempo dado }\end{array}$ & Por definir & Por definir & $\begin{array}{l}\text { Por } \\
\text { definir }\end{array}$ \\
\hline & GOAL_08 & & $\begin{array}{l}\text { Número de presta- } \\
\text { dores de servicios } \\
\text { turísticos con RNT }\end{array}$ & $\begin{array}{l}\text { Número de presta- } \\
\text { dores con RNT y que } \\
\text { reportan contribución } \\
\text { parafiscal en turismo- } \\
\text { colombia.gov.co }\end{array}$ & 27.206 & 35.272 & $30 \%$ \\
\hline \multirow{8}{*}{ 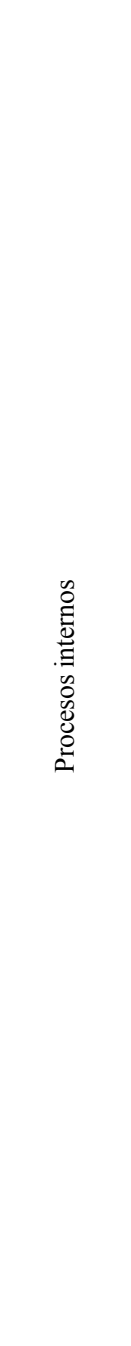 } & GOAL_09 & & $\begin{array}{l}\text { Porcentaje de ocupa- } \\
\text { ción hotelera }\end{array}$ & $\begin{array}{l}\text { Número de noches de } \\
\text { hospedaje disponibles } \\
\text { por año/Número de } \\
\text { noches reservadas } \\
\text { efectivas por año* } \\
100 \%\end{array}$ & $56 \%$ & $62 \%$ & $11 \%$ \\
\hline & GOAL_10 & & $\begin{array}{l}\text { Número de pasajeros } \\
\text { llegados en cruceros }\end{array}$ & $\begin{array}{l}\text { Número de turistas } \\
\text { provenientes de cru- } \\
\text { ceros calculado por } \\
\text { Migración Colombia } \\
\text { por año }\end{array}$ & 383.279 & 450.000 & $17 \%$ \\
\hline & GOAL_11 & & $\begin{array}{l}\text { Número de turistas } \\
\text { extranjeros }\end{array}$ & $\begin{array}{l}\text { Número de turistas } \\
\text { extranjeros calculado } \\
\text { por Migración Co- } \\
\text { lombia por año }\end{array}$ & 3.259 .590 & 6.000 .089 & $84 \%$ \\
\hline & GOAL_12 & KPI-3 & $\begin{array}{l}\text { Visitantes no resi- } \\
\text { dentes que pernoctan } \\
\text { en un alojamiento } \\
\text { del RNT }\end{array}$ & $\begin{array}{l}\text { Número de turistas } \\
\text { no residentes que } \\
\text { pernoctan en un aloja- } \\
\text { miento con RNT }\end{array}$ & 3.898 .065 & 5.100 .000 & $31 \%$ \\
\hline & GOAL_13 & & $\begin{array}{l}\text { Número de sillas } \\
\text { utilizadas en rutas } \\
\text { aéreas nacionales e } \\
\text { internacionales }\end{array}$ & $\begin{array}{l}\text { Número de sillas ven- } \\
\text { didas calculado por la } \\
\text { Aerocivil }\end{array}$ & 35.620 .713 & 45.300 .000 & $27 \%$ \\
\hline & GOAL_14 & KPI-4 & $\begin{array}{l}\text { Número de destinos } \\
\text { culturales y ambienta- } \\
\text { les posicionados }\end{array}$ & $\begin{array}{l}\text { Número de sitios } \\
\text { reconocidos por or- } \\
\text { ganismos culturales y } \\
\text { medioambientales del } \\
\text { Gobierno nacional }\end{array}$ & Por definir & Por definir & $\begin{array}{l}\text { Por } \\
\text { definir }\end{array}$ \\
\hline & GOAL_15 & & $\begin{array}{l}\text { Nuevas marcas anclas } \\
\text { de talla mundial en } \\
\text { hoteles y parques } \\
\text { temáticos para Co- } \\
\text { lombia }\end{array}$ & $\begin{array}{l}\text { Número de marcas } \\
\text { anclas registradas en } \\
\text { el MincIT }\end{array}$ & - & 3 & $300 \%$ \\
\hline & GOAL_16 & & $\begin{array}{l}\text { Zonas turísticas espe- } \\
\text { ciales para Colombia }\end{array}$ & $\begin{array}{l}\text { Número de zonas } \\
\text { turísticas especiales } \\
\text { aprobadas por la DIAN }\end{array}$ & - & 3 & $300 \%$ \\
\hline
\end{tabular}




\begin{tabular}{|c|c|c|c|c|c|c|c|}
\hline Perspectiva & Código & $O C D E$ & $\begin{array}{l}\text { Descripción del } \\
\text { indicador }\end{array}$ & Medición & Actual & Objetivo & Brecha \\
\hline \multirow{4}{*}{ 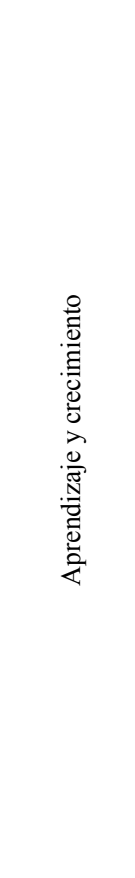 } & GOAL_17 & & $\begin{array}{l}\text { Número de guías } \\
\text { turísticos en cursos de } \\
\text { idiomas }\end{array}$ & $\begin{array}{l}\text { Número de guías que } \\
\text { hayan aprobado los } \\
\text { cursos registrados } \\
\text { en turismocolombia. } \\
\text { gov.co }\end{array}$ & 100 & 200 & $100 \%$ \\
\hline & GOAL_18 & & $\begin{array}{l}\text { Número de policías } \\
\text { de turismo en cur- } \\
\text { sos de inglés }\end{array}$ & $\begin{array}{l}\text { Número de policías } \\
\text { que hayan aprobado } \\
\text { los cursos registrados } \\
\text { en turismocolombia. } \\
\text { gov.co }\end{array}$ & 300 & 600 & $100 \%$ \\
\hline & GOAL_19 & KPI-5 & $\begin{array}{l}\text { Satisfacción del visi- } \\
\text { tante y su intención de } \\
\text { recomendar y repetir } \\
\text { la visita }\end{array}$ & $\begin{array}{l}\text { Determinado por } \\
\text { varios factores, inclu- } \\
\text { yendo la valoración } \\
\text { de la experiencia del } \\
\text { turista, la recomen- } \\
\text { dación a otros, las } \\
\text { opiniones en medios } \\
\text { sociales, blogs y otros } \\
\text { medios, todo lo cual } \\
\text { juega un papel clave } \\
\text { en la toma de decisión } \\
\text { de otros viajeros. }\end{array}$ & Por definir & Por definir & $\begin{array}{l}\text { Por } \\
\text { definir }\end{array}$ \\
\hline & GOAL_20 & KPI-6 & $\begin{array}{l}\text { Diversificación y cre- } \\
\text { cimiento de mercados }\end{array}$ & $\begin{array}{l}\text { Número de mercados } \\
\text { de turismo fuente }\end{array}$ & Por definir & Por definir & $\begin{array}{l}\text { Por } \\
\text { definir }\end{array}$ \\
\hline
\end{tabular}

\section{Indicadores core}

Tabla 8. Indicadores de desempeño e impacto del turismo

\begin{tabular}{|c|l|}
\hline \multicolumn{1}{|c|}{$I D$} & \multicolumn{1}{c|}{ Descripción } \\
\hline KPI-01 & $\begin{array}{l}\text { Producto interno bruto (PIB) en alojamiento } \\
\text { y servicios de comida }\end{array}$ \\
\hline KPI-02 & $\begin{array}{l}\text { Ingreso por turismo receptivo por visitante } \\
\text { internacional }\end{array}$ \\
\hline KPI-03 & $\begin{array}{l}\text { Pernoctación de turistas extranjeros en todo } \\
\text { tipo de alojamientos }\end{array}$ \\
\hline
\end{tabular}

Fuente: Dupeyras y MacCallum (2013).

Tabla 9. Indicadores de atractivos de los destinos turísticos

\begin{tabular}{|c|l|}
\hline$I D$ & \multicolumn{1}{|c|}{ Descripción } \\
\hline KPI-04 & Recursos culturales, naturales y biodiversidad \\
\hline KPI-05 & Satisfacción del visitante \\
\hline
\end{tabular}

Fuente: Dupeyras y MacCallum (2013).

\section{Indicadores suplementarios}

Se identificó la importancia de algunos indicadores propuestos que se adicionaron de acuerdo con su relevancia de medición para el negocio.

Tabla 10. Indicadores de desempeño e impacto del turismo

\begin{tabular}{|c|c|}
\hline ID & Descripción \\
\hline KPI-06 & Diversificación y crecimiento de mercados \\
\hline
\end{tabular}

Fuente: Dupeyras y MacCallum (2013).

Tabla 11. Capacidad de un destino para ofrecer servicios turísticos competitivos y de calidad

\begin{tabular}{|c|l|}
\hline ID & \multicolumn{1}{|c|}{ Descripción } \\
\hline KPI-07 & Diversificación y crecimiento de mercados \\
\hline KPI-08 & $\begin{array}{l}\text { Índice de precios al consumidor para el } \\
\text { turismo }\end{array}$ \\
\hline
\end{tabular}

Fuente: Dupeyras y Maccallum (2013). 


\subsection{Diagnóstico externo}

A continuación, se desarrollan tres análisis de diagnóstico externos que buscan dar un vistazo a los principales retos que podría enfrentar un proceso de transformación digital por fuera del entorno del Viceministerio de Turismo. Se presenta una matriz de las debilidades, oportunidades, fortalezas y amenazas que posee el sector turístico en el escenario de negocio propuesto.

\subsubsection{DOFA}

Tabla 12. Matriz DOFA

\begin{tabular}{|c|c|c|c|}
\hline \multicolumn{2}{|r|}{ Fortalezas } & \multicolumn{2}{|r|}{ Debilidades } \\
\hline F1 & $\begin{array}{l}\text { Segundo país en biodiversidad en el mundo: } \\
\text { primero en aves y orquídeas; segundo en } \\
\text { plantas, anfibios y mariposas; y tercero } \\
\text { en plantas y reptiles. }\end{array}$ & D1 & $\begin{array}{l}\text { Poca preparación tanto del personal de aten- } \\
\text { ción del sector turístico como de los guías de } \\
\text { turismo. }\end{array}$ \\
\hline $\mathrm{F} 2$ & $\begin{array}{l}\text { Colombia tiene el } 44 \% \text { de los páramos de } \\
\text { Suramérica. }\end{array}$ & D2 & Infraestructura turística deficiente. \\
\hline F3 & $\begin{array}{l}\text { Territorio rico y valioso en patrimonio } \\
\text { cultural. }\end{array}$ & D3 & Poca divulgación y promoción del turismo. \\
\hline $\mathrm{F} 4$ & Ubicación geográfica privilegiada. & D4 & Bajo porcentaje de bilingüismo. \\
\hline \multirow[t]{2}{*}{ F5 } & $\begin{array}{l}\text { Gran variedad gastronómica, folclórica y } \\
\text { cultural. }\end{array}$ & D5 & $\begin{array}{l}\text { Poca concientización de los colombianos por } \\
\text { su historia y sus sitios turísticos. }\end{array}$ \\
\hline & & D6 & Poca o mala señalización turística. \\
\hline \multicolumn{2}{|r|}{ Amenazas } & \multicolumn{2}{|r|}{ Oportunidades } \\
\hline A1 & $\begin{array}{l}\text { Minería ilegal y su impacto en los recursos } \\
\text { naturales. }\end{array}$ & $\mathrm{O} 1$ & $\begin{array}{l}\text { Explotar el gran potencial de biodiversidad } \\
\text { con el que cuenta el país. }\end{array}$ \\
\hline A2 & $\begin{array}{l}\text { Baja seguridad en algunas zonas donde lide- } \\
\text { ran grupos al margen de la ley. }\end{array}$ & $\mathrm{O} 2$ & $\begin{array}{l}\text { Fortalecer los corredores turísticos y cultura- } \\
\text { les de las regiones. }\end{array}$ \\
\hline A3 & $\begin{array}{l}\text { Pocas políticas de protección de especies en } \\
\text { peligro de extinción. }\end{array}$ & $\mathrm{O} 3$ & $\begin{array}{l}\text { Diseñar y desarrollar productos turísticos que } \\
\text { propendan a generar experiencias únicas y de } \\
\text { impacto para los turistas. }\end{array}$ \\
\hline A4 & $\begin{array}{l}\text { Competidores mejor organizados y/o con } \\
\text { mejores ofertas turísticas. }\end{array}$ & $\mathrm{O} 4$ & $\begin{array}{l}\text { Fortalecer las alianzas entre el sector público } \\
\text { y el privado para potenciar la oferta de valor } \\
\text { en la región. }\end{array}$ \\
\hline A5 & $\begin{array}{l}\text { La imagen negativa del país que aún se man- } \\
\text { tiene en el mundo. }\end{array}$ & O5 & $\begin{array}{l}\text { Generar leyes que apoyen y potencien el } \\
\text { sector turístico, que mejoren el ingreso y/o } \\
\text { controlen el tema de los impuestos. }\end{array}$ \\
\hline & & O6 & $\begin{array}{l}\text { Fortalecer la planificación enfocada en el } \\
\text { desarrollo sostenible }\end{array}$ \\
\hline & & $\mathrm{O} 7$ & $\begin{array}{l}\text { Incrementar la oferta laboral debido al } \\
\text { aumento de las ofertas turísticas. }\end{array}$ \\
\hline
\end{tabular}

Fuente: Elaboración propia. 
Por otra parte, se realizaron dos análisis adicionales al DOFA: uno político, económico, social y tecnológico (PESTAL) de las principales variables que pueden afectar las estrategias, y otro que corresponde a la interacción directa con prestadores de servicios turísticos y turistas, con el fin de conocer sus opiniones por medio de entrevistas anónimas.

\subsubsection{Interacción directa con la población}

Se procedió a entrevistar a los diferentes prestadores de servicios turísticos para analizar su percepción sobre el turismo en Boyacá. Para ello se utilizó el método de recolección de información de entrevista

\subsubsection{PESTAL}

Tabla 13. Tabla de análisis PESTAL

\begin{tabular}{|c|c|c|c|c|}
\hline$I D$ & Tipo de impacto & Nivel & Descripción & Análisis \\
\hline PEST-P-01 & Político & Alto & $\begin{array}{l}\text { Principios genera- } \\
\text { les de la industria } \\
\text { turística }\end{array}$ & $\begin{array}{l}\text { La Ley } 300 \text { de } 1996 \text { concibe la industria turística } \\
\text { como esencial en el desarrollo del país, por lo que } \\
\text { dispone unos principios generales base que han } \\
\text { venido ajustándose en pro de potenciar el sector } \\
\text { turístico. }\end{array}$ \\
\hline PEST-P-02 & Político & Alto & Estatuto Tributario & $\begin{array}{l}\text { Cumplir con las disposiciones del Estatuto } \\
\text { Tributario, el cual tiene diferentes incentivos } \\
\text { que apoyan a los siguientes sectores: hotelero, } \\
\text { ecoturismo y servicios de turismo a no residentes; } \\
\text { también hay un incentivo especial al archipiélago de } \\
\text { San Andrés (Ley } 1607 \text { de 2012). }\end{array}$ \\
\hline PEST-P-03 & Político & Alto & Legislación laboral & $\begin{array}{l}\text { Cumplir a cabalidad las disposiciones } \\
\text { reglamentarias correspondientes a la contratación } \\
\text { laboral, garantizando el pago de las debidas } \\
\text { prestaciones y beneficios que ordena la ley. }\end{array}$ \\
\hline PEST-P-04 & Político & Alto & $\begin{array}{l}\text { Leyes, decretos y } \\
\text { resoluciones que } \\
\text { apliquen al modelo } \\
\text { de negocio }\end{array}$ & $\begin{array}{l}\text { Se deben acatar las reglamentaciones que el } \\
\text { Gobierno nacional defina para el sector turístico y } \\
\text { validar no solo los decretos de orden nacional, sino } \\
\text { también aquellos de orden departamental, según se } \\
\text { disponga. }\end{array}$ \\
\hline PEST-E-01 & Económico & Alto & $\begin{array}{l}\text { Nivel de confianza } \\
\text { del consumidor }\end{array}$ & $\begin{array}{l}\text { Es fundamental generar niveles de confianza con } \\
\text { los turistas en todos los aspectos de servicios que } \\
\text { se prestan, y esto se logra entregando servicios de } \\
\text { calidad. }\end{array}$ \\
\hline PEST-E-02 & Económico & Medio & Índices de precios & $\begin{array}{l}\text { La alta competencia obliga a fortalecer los servicios } \\
\text { y a ofrecer valores agregados y diferenciadores que } \\
\text { permitan manejar precios competitivos con servicios } \\
\text { de calidad. }\end{array}$ \\
\hline PEST-E-03 & Económico & Medio & $\begin{array}{l}\text { Tasas de creci- } \\
\text { miento del sector } \\
\text { turístico }\end{array}$ & $\begin{array}{l}\text { El índice de turistas ha venido creciendo en los } \\
\text { últimos años, pero es necesario fortalecer no solo } \\
\text { los servicios, sino todo el entorno (rutas, corredores, } \\
\text { accesos, seguridad, etc.), de esta manera se genera } \\
\text { confianza en el turista. }\end{array}$ \\
\hline
\end{tabular}




\begin{tabular}{|c|c|c|c|c|}
\hline$I D$ & Tipo de impacto & Nivel & Descripción & Análisis \\
\hline PEST-S-01 & Social & Bajo & $\begin{array}{l}\text { Población y sus } \\
\text { condiciones de } \\
\text { vida }\end{array}$ & $\begin{array}{l}\text { La gran diversidad de climas, regiones, gastronomía } \\
\text { y destinos turísticos a nivel nacional permite ofrecer } \\
\text { servicios a prácticamente todos los estratos sociales } \\
\text { y le posibilita al sector turístico tener una demanda } \\
\text { constante, que debe mejorar para potenciarse cada } \\
\text { día. }\end{array}$ \\
\hline PEST-S-02 & Social & Bajo & $\begin{array}{l}\text { Patrones de con- } \\
\text { sumo }\end{array}$ & $\begin{array}{l}\text { Analizar diferentes tendencias en los destinos y } \\
\text { servicios entregados para tener estadísticas de } \\
\text { flujos permitirá estar mejor preparados y fortalecer } \\
\text { las falencias en pro de incrementar los niveles de } \\
\text { satisfacción de los turistas. }\end{array}$ \\
\hline PEST-T-01 & Tecnológico & Medio & $\begin{array}{l}\text { Disponibilidad } \\
\text { tecnológica }\end{array}$ & $\begin{array}{l}\text { En la actualidad existen plataformas que permiten } \\
\text { potenciar el marketing de los prestadores de } \\
\text { servicios y de los corredores turísticos, así como } \\
\text { también hay herramientas de analítica para explotar } \\
\text { de manera más eficiente la promoción de los } \\
\text { servicios. }\end{array}$ \\
\hline PEST-T-02 & Tecnológico & Medio & $\begin{array}{l}\text { Actualización e } \\
\text { integración }\end{array}$ & $\begin{array}{l}\text { Sobre la base de la premisa anterior, se pueden } \\
\text { encontrar soluciones que permitan gestionar } \\
\text { el modelo de negocio del sector turístico de } \\
\text { una manera óptima desde el punto de vista de } \\
\text { trazabilidad y organización (segmentación). }\end{array}$ \\
\hline
\end{tabular}

Fuente: Elaboración propia.

anónima. Las respuestas consolidadas se presentan a continuación:

1. ¿Qué tipo de turista (mercado) ingresa a Boyacá?

- $38 \%$ Bogotá.

- $14 \%$ Llanos Orientales.

- $11 \%$ Santander.

- $10 \%$ Eje Cafetero.

- $9 \%$ Antioquia.

- $12 \%$ Otros Colombia.

- $6 \%$ Extranjeros (Estados Unidos, Alemania, España, Austria, Chile).
2. ¿Qué cree que se necesita para fortalecer y mantener el turismo en Boyacá?

- Unión por parte de los prestadores de servicios turísticos.

- Fortalecimiento de la oficina de turismo.

- Coordinación de la oferta.

- Recomendación de acceso a los atractivos turísticos.

- Señalización vial.

- Publicidad en línea.

- Promoción. 
3. ¿Qué aspectos de Boyacá considera Ud. que podrían afectar negativamente el turismo en el departamento? ¿Cómo cree que se podría contrarrestar?

- Contaminación y daño ambiental.

- Embellecimiento de los municipios, aseo y organización.

- Cultura turística.

4. ¿Qué fortalezas y debilidades percibe Ud. en el sector?

Fortalezas:

- Crecimiento económico en el municipio gracias al turismo.

- Segundo en actividad económica, luego de la agricultura.

- Fuerte presencia de entidades gubernamentales.

Debilidades:

- Falta de integración del sector (asociativo) hoteles y restaurantes.

- Falta de cooperatividad.

5. ¿Ha sido capacitado por parte de instituciones del gobierno para ofrecer los servicios turísticos?

- $50 \%$ SÍ.

- $50 \%$ NO.

- El SENA exige un mínimo de 60 personas para capacitarse, pero generalmente los hoteles no cuentan con una planta de empleados suficiente para poder recibir estas capacitaciones, por eso sugieren que se puedan capacitar en línea.

6. ¿Cómo se enteran habitualmente sus clientes de su negocio?

- $44 \%$ redes sociales.

- $32 \%$ pasarelas (Decameron, Booking, etc.).

- $19 \%$ voz a voz (recomendación de anteriores clientes).

- $5 \%$ sitio web propio.

7. ¿Está usted inscrito en el RNT?

- $60 \%$ SÍ

- $40 \% \mathrm{NO}$

8. ¿Tiene servicio de Internet?

- $\quad 100 \%$ SÍ

- Los mismos clientes (turistas) exigen que los sitios cuenten con Internet.

\subsubsection{Hallazgos}

En la tabla 14 se presentan los principales hallazgos identificados luego del análisis interno y externo.

\section{Estrategias de transformación digital}

Con el fin de generar una transformación que cumpla con la visión estratégica del sector turístico consignada en el Plan Sectorial de Turismo (MincIT, 2019), se muestra la estructura del paso a paso para la definición de estrategias de transformación digital. 
Tabla 14. Hallazgos de la situación actual

\begin{tabular}{|c|c|c|c|c|}
\hline$I D$ & Descripción & Análisis & Justificación & Severidad \\
\hline H01 & $\begin{array}{l}\text { Importancia } \\
\text { regional del turismo }\end{array}$ & $\begin{array}{l}\text { Interacción } \\
\text { directa con la } \\
\text { población }\end{array}$ & $\begin{array}{l}\text { Existe la necesidad, por parte de los prestadores } \\
\text { turísticos, de agrupar la oferta turística por clústeres, } \\
\text { esto con el fin de ofrecerles a los turistas un } \\
\text { portafolio de servicios completo. }\end{array}$ & Alta \\
\hline $\mathrm{H} 02$ & $\begin{array}{l}\text { Oportunidad de } \\
\text { mercado }\end{array}$ & $\begin{array}{l}\text { Modelo de } \\
\text { negocio }\end{array}$ & $\begin{array}{l}\text { Existe una oportunidad importante de impulsar } \\
\text { económica y socialmente el sector por medio de la } \\
\text { venta de servicios turísticos y de apoyar el sector } \\
\text { mediante TI. }\end{array}$ & Alta \\
\hline H03 & $\begin{array}{l}\text { Impuestos que } \\
\text { generen valor }\end{array}$ & $\begin{array}{l}\text { Modelo } \\
\text { financiero }\end{array}$ & $\begin{array}{l}\text { El aporte de la contribución parafiscal es la fuente } \\
\text { más importante de impulso al sector, por lo que debe } \\
\text { mejorarse la interacción en el pago de aportes y que } \\
\text { estos generen valor directo a los prestadores. }\end{array}$ & Media \\
\hline H04 & $\begin{array}{l}\text { Alineación entre } \\
\text { los objetivos y la } \\
\text { ejecución }\end{array}$ & $\begin{array}{l}\text { Modelo } \\
\text { estratégico }\end{array}$ & $\begin{array}{l}\text { Se identifican los objetivos y la línea de trabajo, } \\
\text { pero el cómo se van a ejecutar no es claro ni está } \\
\text { explícito. }\end{array}$ & Media \\
\hline H05 & $\begin{array}{l}\text { Escaso personal de } \\
\text { TI en el MinciT }\end{array}$ & $\begin{array}{l}\text { Modelo de } \\
\text { capacidades }\end{array}$ & $\begin{array}{l}\text { Las capacidades internas de ejecución de proyectos } \\
\text { en TI son limitadas, por eso deben buscarse } \\
\text { las capacidades externamente por medio de la } \\
\text { adquisición de talento. }\end{array}$ & Media \\
\hline H06 & $\begin{array}{l}\text { Información que } \\
\text { genera valor }\end{array}$ & $\begin{array}{l}\text { Modelo de } \\
\text { información }\end{array}$ & $\begin{array}{l}\text { Existe información valiosa que no se encuentra } \\
\text { integrada ni dispuesta para el público de forma } \\
\text { agradable y fácil de utilizar. }\end{array}$ & Alta \\
\hline H07 & $\begin{array}{l}\text { Competitividad en } \\
\text { Latinoamérica }\end{array}$ & DOFA & $\begin{array}{l}\text { La más importante amenaza es la no incorporación } \\
\text { de TI en el apoyo para el sector. Esto puede generar } \\
\text { un rezago en comparación con otros países de la } \\
\text { región en lo referente a la captación de recursos de } \\
\text { turistas extranjeros. }\end{array}$ & Media \\
\hline H08 & $\begin{array}{l}\text { Alineación política } \\
\text { alrededor del sector }\end{array}$ & PESTAL & $\begin{array}{l}\text { Existen riesgos políticos que pueden afectar la } \\
\text { implementación de la estrategia, por ello se debe } \\
\text { buscar un consenso generalizado entre los diferentes } \\
\text { actores en la necesidad de impulsar el turismo por } \\
\text { medio de TI. }\end{array}$ & Alta \\
\hline
\end{tabular}

Fuente: Elaboración propia.

Estas estrategias se acoplan con el Plan Estratégico de Tecnologías de la Información 2019-2022 (PETI) del Ministerio de Comercio, Industria y Turismo (Mincit) (ver Corporación Colombia Digital, 2018).

\subsection{Motivadores de negocio}

Se identificaron los siguientes motivadores de negocio, por los cuales sería importante implementar el Plan de Transformación propuesto. Esto tiene como fin reducir la estrategia a una justificación del para qué se realizaría y cómo se ejecutaría. 
Tabla 15. Motivadores de negocio

\begin{tabular}{|c|c|c|c|}
\hline$I D$ & Motivador & Objetivos (para qué) & Estrategias (cómo) \\
\hline \multirow{3}{*}{ M1 } & \multirow{3}{*}{$\begin{array}{l}\text { Promover a nivel } \\
\text { nacional e interna- } \\
\text { cional la visita a } \\
\text { destinos turísticos } \\
\text { colombianos. }\end{array}$} & $\begin{array}{l}\text { Posicionar a Colombia como un } \\
\text { destino atractivo para conocer e } \\
\text { invertir. }\end{array}$ & $\begin{array}{l}\text { Brindar herramientas de promoción turística que } \\
\text { ayuden a generar mayor consumo de servicios } \\
\text { turísticos. }\end{array}$ \\
\hline & & $\begin{array}{l}\text { Liderar las estadísticas a nivel } \\
\text { regional por medio de la acción y el } \\
\text { seguimiento de estas. }\end{array}$ & $\begin{array}{l}\text { Generar análisis de datos de las estadísticas cla- } \\
\text { ves del sector para que sean comparadas interna } \\
\text { y externamente con el fin de orientar la mejora } \\
\text { continua. }\end{array}$ \\
\hline & & $\begin{array}{l}\text { Mejorar la experiencia de viaje del } \\
\text { turista mediante la utilización de } \\
\text { nuevas tecnologías. }\end{array}$ & $\begin{array}{l}\text { Proveer a los turistas herramientas que ayuden al } \\
\text { mejoramiento de su experiencia de viaje. }\end{array}$ \\
\hline \multirow{3}{*}{ M2 } & \multirow{3}{*}{$\begin{array}{l}\text { Generar prospe- } \\
\text { ridad económica, } \\
\text { social y ambiental } \\
\text { para todos los co- } \\
\text { lombianos. }\end{array}$} & $\begin{array}{l}\text { Aumentar las exportaciones de } \\
\text { servicios turísticos y la atracción de } \\
\text { divisas e inversión al país. }\end{array}$ & $\begin{array}{l}\text { Difundir y promover los atractivos turísticos y el } \\
\text { paquete de servicios turísticos que posee el país. }\end{array}$ \\
\hline & & $\begin{array}{l}\text { Expandir el número de empleos } \\
\text { directos e indirectos que genera el } \\
\text { sector a lo largo del país y mejorar el } \\
\text { nivel de vida de los colombianos. }\end{array}$ & $\begin{array}{l}\text { Aumentar la demanda de consumo de servicios } \\
\text { turísticos con el fin de que la oferta de servi- } \\
\text { cios por parte de los prestadores se amplíe. } \\
\text { Impulsar la contratación formal de más colom- } \\
\text { bianos para aprovechar que el sector es intensivo } \\
\text { en mano de obra. }\end{array}$ \\
\hline & & $\begin{array}{l}\text { Preservar el medio ambiente como } \\
\text { patrimonio de la humanidad. }\end{array}$ & $\begin{array}{l}\text { Incentivar la implementación de las normas téc- } \\
\text { nicas sectoriales con el fin de apoyar el turismo } \\
\text { sostenible en las regiones. }\end{array}$ \\
\hline \multirow{3}{*}{ M3 } & \multirow{3}{*}{$\begin{array}{l}\text { Impulsar la crea- } \\
\text { ción de empresas } \\
\text { de vocación turísti- } \\
\text { ca y respetuosas de } \\
\text { la ley en Colombia. }\end{array}$} & $\begin{array}{l}\text { Brindar las tecnologías necesarias } \\
\text { para facilitar las actividades eco- } \\
\text { nómicas dentro de la legalidad y la } \\
\text { contribución al país. }\end{array}$ & $\begin{array}{l}\text { Implementar la legislación vigente en la activi- } \\
\text { dad económica relacionada con el sector en pro } \\
\text { de garantizar el bien común. }\end{array}$ \\
\hline & & $\begin{array}{l}\text { Mejorar la competitividad de los } \\
\text { sectores económicos ligados al } \\
\text { turismo. }\end{array}$ & $\begin{array}{l}\text { Promover la educación orientada al mejoramien- } \\
\text { to de los procesos, el entorno de negocios, el } \\
\text { bilingüismo, la sostenibilidad y la experiencia } \\
\text { ofrecida a los turistas. }\end{array}$ \\
\hline & & $\begin{array}{l}\text { Garantizar un nivel de servicio } \\
\text { superior de los productos turísticos } \\
\text { ofrecidos legalmente en el país. }\end{array}$ & $\begin{array}{l}\text { Mejorar la recepción y el trámite de demandas o } \\
\text { denuncias contra prestadores de servicios turís- } \\
\text { ticos en pro de mejorar el servicio que se presta } \\
\text { a los turistas. }\end{array}$ \\
\hline
\end{tabular}

Fuente: Elaboración propia.

\subsection{Análisis de brechas}

Se muestran en la tabla 16 algunas de las brechas encontradas entre los motivadores de negocio y el diagnóstico de la situación actual.

\subsection{Estrategias e iniciativas de transformación digital}

En las tablas 17 a 26 y en las figuras 6 a 10 se presentan las estrategias e iniciativas de transformación digital que se plantearon con el propósito de cumplir los objetivos estratégicos y cerrar las brechas identificadas anteriormente. Cada una de las estrategias tiene como distintivo el nombre de un ave que la representa y posee una identidad visual propia con el fin de poder realizar una referenciación fácil a cada una de ellas en este documento y al momento de su implementación. 
Tabla 16. Análisis de brechas

\begin{tabular}{|c|c|c|c|}
\hline Gap-ID & Tipo/Nombre & Descripción & $\begin{array}{l}\text { Iniciativas para } \\
\text { normalizar la } \\
\quad \text { brecha }\end{array}$ \\
\hline GAP-1 & $\begin{array}{l}\text { Crear } \\
\text { Estructurar la } \\
\text { información del RNT, } \\
\text { de los inventarios y } \\
\text { corredores. }\end{array}$ & $\begin{array}{l}\text { Con la información del RNT, de los inventarios y } \\
\text { corredores turísticos, diseñar un modelo de datos que } \\
\text { permita darle una estructura lógica y funcional a la } \\
\text { información que actualmente está dispersa en hojas } \\
\text { de cálculo. }\end{array}$ & P 1.1 \\
\hline GAP-2 & $\begin{array}{l}\text { Crear } \\
\text { Disponibilidad de la } \\
\text { información del RNT, } \\
\text { de los inventarios y } \\
\text { corredores. }\end{array}$ & $\begin{array}{l}\text { Diseñar servicios digitales que permitan exponer al } \\
\text { público en general la información estructurada del } \\
\text { RNT, de los inventarios y corredores turísticos. }\end{array}$ & $\begin{array}{l}\text { P } 1.2 \\
\text { P } 1.3\end{array}$ \\
\hline GAP-3 & $\begin{array}{l}\text { Crear } \\
\text { Asegurar el acceso a la } \\
\text { información del RNT, } \\
\text { de los inventarios y } \\
\text { corredores. }\end{array}$ & $\begin{array}{l}\text { Definir los componentes de seguridad de acceso } \\
\text { a la información que garanticen el acceso a los } \\
\text { diversos actores según su rol en la cadena de valor } \\
\text { del negocio. }\end{array}$ & $\begin{array}{l}\text { P } 1.2 \\
\text { P } 1.4\end{array}$ \\
\hline GAP-4 & $\begin{array}{l}\text { Crear } \\
\text { Mejorar el time to } \\
\text { market. }\end{array}$ & $\begin{array}{l}\text { Especificar un proceso que permita incorporar } \\
\text { prácticas ágiles de desarrollo de software y } \\
\text { administración de la plataforma que permitan } \\
\text { optimizar el tiempo de puesta en marcha de los nuevos } \\
\text { sistemas y la evolución de los existentes. }\end{array}$ & $\begin{array}{l}\text { P } 1.2 \\
\text { P } 1.3 \\
\text { P } 1.5\end{array}$ \\
\hline GAP-5 & $\begin{array}{l}\text { Modificar } \\
\text { Mejorar la experiencia } \\
\text { del usuario. }\end{array}$ & $\begin{array}{l}\text { Diseñar una experiencia de usuario (UX) mejorada } \\
\text { multidispositivo que permita atraer y fidelizar a los } \\
\text { actores de la cadena de valor del turismo. }\end{array}$ & $\begin{array}{l}\text { P } 1.2 \\
\text { P } 1.5\end{array}$ \\
\hline GAP-6 & $\begin{array}{l}\text { Crear } \\
\text { Brindar información } \\
\text { a otros entes } \\
\text { gubernamentales. }\end{array}$ & $\begin{array}{l}\text { Diseñar e incorporar un mecanismo de exposición } \\
\text { de la información requerida por los entes } \\
\text { gubernamentales (DANE, DIAN). }\end{array}$ & $\begin{array}{l}\text { P } 1.6 \\
\text { P } 2.6\end{array}$ \\
\hline GAP-7 & $\begin{array}{l}\text { Crear } \\
\text { Posicionamiento de } \\
\text { marca. }\end{array}$ & $\begin{array}{l}\text { Diseñar una estrategia de marketing digital para } \\
\text { promover los atractivos turísticos del país y la } \\
\text { legalidad de los operadores turísticos. }\end{array}$ & Р 1.7 \\
\hline GAP-8 & $\begin{array}{l}\text { Crear } \\
\text { Indicador de visibilidad. }\end{array}$ & $\begin{array}{l}\text { Tomar medidas con respecto al tráfico hacia los } \\
\text { portales de turismo del Estado colombiano. }\end{array}$ & P 1.8 \\
\hline
\end{tabular}

Fuente: Elaboración propia.

\subsubsection{E1 - Colibrí-Sistema integrado de turismo}

Figura 6. Identidad visual de la Estrategia Colibrí

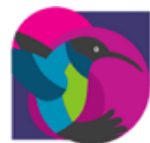

Fuente: Elaboración propia. 
Tabla 17. Descripción detallada de la Estrategia Colibrí

\begin{tabular}{|l|l|}
\hline \multicolumn{2}{|c|}{ E1-Colibri-Sistema integrado de turismo } \\
\hline Descripción & $\begin{array}{l}\text { Esta estrategia integra la información del Registro Nacional de Turismo (RNT), de los inven- } \\
\text { tarios y corredores turísticos en una arquitectura de solución que soportará el resto de las } \\
\text { estrategias planteadas en el Plan. Su objetivo principal es proveer al turista de información } \\
\text { clave y ayudar a la promoción turística del sector con su implementación territorial. }\end{array}$ \\
\hline Tipo & Promoción turística y arquitectura de solución \\
\hline $\begin{array}{l}\text { Impacto } \\
\text { organizacional }\end{array}$ & $\begin{array}{l}\text { Aporta de forma directa a los objetivos estratégicos de promoción turística e inicia la inte- } \\
\text { racción entre el turista, las regiones y el Gobierno central; como resultado, genera mejores } \\
\text { datos para que sea posible utilizarlos en las siguientes estrategias en pro del sector. }\end{array}$ \\
\hline $\begin{array}{l}\text { Requisitos de } \\
\text { implementación }\end{array}$ & $\begin{array}{l}\text { Compromiso desde los altos funcionarios del Ministerio de Comercio, Industria y Turis- } \\
\text { mo para adelantar el Plan. } \\
\text { Garantizar partidas presupuestarias a las iniciativas y un plan financiero de largo plazo. }\end{array}$ \\
\hline $\begin{array}{l}\text { Origen de la } \\
\text { estrategia }\end{array}$ & \begin{tabular}{l} 
Hallazgos: H1, H3, H6. \\
\hline
\end{tabular}
\end{tabular}

Fuente: Elaboración propia.

Tabla 18. Detalle de las iniciativas de la Estrategia Colibrí

\begin{tabular}{|c|c|c|c|}
\hline Estrategia & $\begin{array}{l}\text { ID_- } \\
\text { iniciativa }\end{array}$ & Nombre de la iniciativa & Descripción de la iniciativa \\
\hline \multirow{8}{*}{$\begin{array}{l}\text { Estrategia } \\
\text { E1 Colibrí }\end{array}$} & P 1.1 & $\begin{array}{l}\text { Cargue de información y } \\
\text { calidad de datos }\end{array}$ & $\begin{array}{l}\text { Almacenamiento de los registros contenidos en Excel en } \\
\text { bases de datos. }\end{array}$ \\
\hline & P 1.2 & $\begin{array}{l}\text { Diseño de la arquitectura } \\
\text { de aplicación }\end{array}$ & $\begin{array}{l}\text { Se refiere a toda la configuración de arquitectura y pruebas } \\
\text { de conceptos para implementar la arquitectura de aplicación. }\end{array}$ \\
\hline & P 1.3 & $\begin{array}{l}\text { Construcción de servicios } \\
\text { backend }\end{array}$ & $\begin{array}{l}\text { Desarrollo de los servicios con todos sus métodos HTTP (GET, } \\
\text { PUT, POST y PATCH) en el backend. }\end{array}$ \\
\hline & P 1.4 & $\begin{array}{l}\text { Servicios de autenticación } \\
\text { y perfilamiento de roles y } \\
\text { usuarios }\end{array}$ & $\begin{array}{l}\text { Desarrollo de los servicios de autenticación y almacena- } \\
\text { miento de datos personales. }\end{array}$ \\
\hline & P 1.5 & Desarrollo del front & $\begin{array}{l}\text { Desarrollo de la arquitectura del front end, acoplamiento del } \\
\text { front y del back junto con la visualización hacia los usuarios } \\
\text { finales en clientes de la web. }\end{array}$ \\
\hline & P 1.6 & Servicios de terceros & $\begin{array}{l}\text { Este proyecto está pensado para el consumo de servicios de } \\
\text { terceros con el fin de ahorrar tiempo y esfuerzo y concentrar- } \\
\text { se en darle valor al turista. }\end{array}$ \\
\hline & P 1.7 & Promoción y marketing & $\begin{array}{l}\text { Configuración de los servicios de búsqueda para que los } \\
\text { usuarios puedan encontrar el sitio en los buscadores predo- } \\
\text { minantes. }\end{array}$ \\
\hline & P 1.8 & Análisis de tráfico & $\begin{array}{l}\text { Integración con herramientas de análisis de tráfico para co- } \\
\text { nocer la acogida y aprender de los usuarios. }\end{array}$ \\
\hline
\end{tabular}

Fuente: Elaboración propia. 


\subsubsection{E2 - Halcón-Analítica}

Figura 7. Identidad visual de la Estrategia Halcón

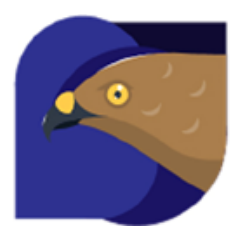

\section{E2 - HALCÓN} Analítica

Fuente: Elaboración propia.

Tabla 19. Descripción detallada de la Estrategia Halcón

\begin{tabular}{|l|l|}
\hline \multicolumn{1}{|l|}{ E2-Halcón-Analitica } \\
\hline Descripción & $\begin{array}{l}\text { Esta estrategia consiste en la generación de valor con base en la información histórica de las } \\
\text { diferentes fuentes del MinciT por medio del descubrimiento, la interpretación y comuni- } \\
\text { cación de patrones significativos en los datos para que estos puedan ser empleados en la } \\
\text { toma de decisiones estratégicas por parte del Ministerio y sirvan como base para un proceso } \\
\text { posterior de predicción. }\end{array}$ \\
\hline $\begin{array}{l}\text { Impacto } \\
\text { organizacional }\end{array}$ & $\begin{array}{l}\text { Toma de decisiones estratégicas, arquitectura de datos. } \\
\text { Ministerio, y esto, a su vez, se verá reflejado en la generación de divisas y en el bienestar de } \\
\text { los actores del turismo. }\end{array}$ \\
\hline $\begin{array}{l}\text { Requisitos de } \\
\text { implementación }\end{array}$ & $\begin{array}{l}\text { Compromiso desde los altos funcionarios del Ministerio de Comercio, Industria y Turis- } \\
\text { mo para adelantar el Plan. } \\
\text { Garantizar partidas presupuestarias a las iniciativas y un plan financiero de largo plazo. } \\
\text { Disponer del talento humano que comparta la visión estratégica y conozca el sector. } \\
\text { Disponer de información histórica del RNT, de los corredores turísticos y prestadores de } \\
\text { servicios turísticos. }\end{array}$ \\
\hline $\begin{array}{l}\text { Origen de la } \\
\text { estrategia }\end{array}$ & \begin{tabular}{l} 
H02, H06, H07. \\
\hline
\end{tabular} \\
\hline
\end{tabular}

Fuente: Elaboración propia.

Tabla 20. Detalle de las iniciativas de la Estrategia Halcón

\begin{tabular}{|c|c|l|l|}
\hline \multirow{2}{*}{ Estrategia } & $\begin{array}{c}\text { ID_ } \\
\text { iniciativa }\end{array}$ & $\begin{array}{c}\text { Nombre de la } \\
\text { iniciativa }\end{array}$ & \multicolumn{1}{c|}{ Descripción de la iniciativa } \\
\hline \multirow{2}{*}{$\begin{array}{c}\text { Estrategia E2 } \\
\text { Halcón }\end{array}$} & P 2.1 & $\begin{array}{l}\text { Fundamentación } \\
\text { para BI/BA }\end{array}$ & $\begin{array}{l}\text { Consiste en todas las actividades básicas para dar comienzo a un } \\
\text { proyecto de analítica. }\end{array}$ \\
\cline { 2 - 4 } & P 2.2 & Diseño BI/BA & $\begin{array}{l}\text { Se refiere a la definición de las estructuras de datos para analíti- } \\
\text { ca, de sus interacciones y comportamientos. }\end{array}$ \\
\cline { 2 - 4 } & P 2.3 & Desarrollo de ETL & $\begin{array}{l}\text { Se trata del desarrollo de los procesos automáticos que permi- } \\
\text { tirán extraer los datos de las diversas fuentes, procesarlos para } \\
\text { darles calidad y forma y, finalmente, almacenarlos en las estruc- } \\
\text { turas de destino. }\end{array}$ \\
\hline
\end{tabular}




\begin{tabular}{|c|c|c|c|}
\hline Estrategia & $\begin{array}{l}I D_{-} \\
\text {iniciativa }\end{array}$ & $\begin{array}{l}\text { Nombre de la } \\
\text { iniciativa }\end{array}$ & Descripción de la iniciativa \\
\hline \multirow{3}{*}{$\begin{array}{l}\text { Estrategia E2 } \\
\text { Halcón }\end{array}$} & P 2.4 & BI & $\begin{array}{l}\text { Radica en el almacenamiento y la administración de informa- } \\
\text { ción histórica para su posterior análisis y toma de decisiones que } \\
\text { apoyen el negocio. }\end{array}$ \\
\hline & P 2.5 & $\begin{array}{l}\text { BA - Los datos } \\
\text { trabajando para } \\
\text { el negocio }\end{array}$ & $\begin{array}{l}\text { Es la exploración y el análisis permanente de la información } \\
\text { histórica para la planeación estratégica futura. }\end{array}$ \\
\hline & P 2.6 & $\begin{array}{l}\text { Transferencia de } \\
\text { información al } \\
\text { DANE }\end{array}$ & $\begin{array}{l}\text { Consiste en la exposición de información a entidades estatales, } \\
\text { en concreto, al DANE. }\end{array}$ \\
\hline
\end{tabular}

Fuente: Elaboración propia

\subsubsection{E3 - Cóndor - Desarrollo institucional}

Figura 8. Identidad visual de la Estrategia Cóndor

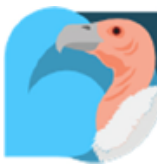

Fuente: Elaboración propia.

Tabla 21. Descripción detallada de la Estrategia Cóndor

\begin{tabular}{|l|l|}
\hline \multicolumn{2}{|c|}{ E3-Cóndor-Desarrollo institucional } \\
\hline Descripción & $\begin{array}{l}\text { Las iniciativas de esta estrategia buscan consolidar el cumplimiento de la normativa rela- } \\
\text { cionada con contribuciones al sector, registro de turistas, pero también de las normativas } \\
\text { de calidad y pago de impuestos, esto con el fin de promover la legalidad y el mejoramiento } \\
\text { continuo de las instituciones que lo gestionan. }\end{array}$ \\
\hline Tipo & Cumplimiento de la normativa vigente \\
\hline $\begin{array}{l}\text { Impacto } \\
\text { organizacional }\end{array}$ & $\begin{array}{l}\text { Aporta de forma directa al objetivo estratégico de consolidar la legalidad, la calidad y el } \\
\text { mejoramiento continuo del sector. }\end{array}$ \\
\hline $\begin{array}{l}\text { Requisitos de } \\
\text { implementación }\end{array}$ & $\begin{array}{l}\text { Compromiso desde los altos funcionarios del Ministerio de Comercio, Industria y Tu- } \\
\text { rismo para adelantar el Plan. } \\
\text { Garantizar partidas presupuestarias a las iniciativas y un plan financiero de largo plazo. } \\
\text { Disponer del talento humano que comparta la visión estratégica y conozca el sector. }\end{array}$ \\
\hline $\begin{array}{l}\text { Origen de la } \\
\text { estrategia }\end{array}$ & \begin{tabular}{l} 
Hallazgos: H3, H4, H6 y H8. \\
\hline
\end{tabular}
\end{tabular}

Fuente: Elaboración propia. 
Tabla 22. Detalle de las iniciativas de la Estrategia Cóndor

\begin{tabular}{|c|c|c|c|}
\hline Estrategia & $\begin{array}{l}\text { ID_- } \\
\text { iniciativa }\end{array}$ & Nombre de la iniciativa & Descripción de la iniciativa \\
\hline \multirow{6}{*}{$\begin{array}{l}\text { Estrategia E3 } \\
\text { Cóndor }\end{array}$} & P.3.1 & Tarjeta de registro hotelero & $\begin{array}{l}\text { Implementación de la tarjeta de registro hotelero digital } \\
\text { para turistas nacionales y extranjeros. }\end{array}$ \\
\hline & P.3.2 & $\begin{array}{l}\text { Construcción de un módulo de } \\
\text { transaccionalidad de ingresos } \\
\text { y contribución parafiscal } \\
\text { (FONTUR) }\end{array}$ & $\begin{array}{l}\text { Este módulo permitirá a los prestadores generar la } \\
\text { contribución parafiscal a FONTUR de manera automática } \\
\text { de acuerdo con los turistas atendidos; además, hará po- } \\
\text { sible la generación del pago por medios electrónicos. }\end{array}$ \\
\hline & P.3.3 & $\begin{array}{l}\text { Verificación y análisis de datos } \\
\text { de ingresos y contribución } \\
\text { parafiscal }\end{array}$ & $\begin{array}{l}\text { Validación de contribuciones y generación de reportes } \\
\text { y alertas tempranas sobre contribución parafiscal. }\end{array}$ \\
\hline & P.3.4 & Administración de PQRS & $\begin{array}{l}\text { Articulación de los actores (turista, prestador, SIC y } \\
\text { MincIT) en la solución de } \mathrm{PQRS} \text {. }\end{array}$ \\
\hline & P.3.5 & $\begin{array}{l}\text { Administración de normas } \\
\text { técnicas }\end{array}$ & $\begin{array}{l}\text { Administración de los certificados de normas técnicas } \\
\text { colombianas (NTC) cumplidas por los prestadores y los } \\
\text { destinos, para lo cual se integra la plataforma actual de } \\
\text { certificacioncalidadturistica.co }\end{array}$ \\
\hline & P.3.6 & Legalidad territorial & $\begin{array}{l}\text { Generación de reportes de visitantes y potencial econó- } \\
\text { mico y social del turismo en la zona. }\end{array}$ \\
\hline
\end{tabular}

Fuente: Elaboración propia.

\subsubsection{E4 - Azulejo - Educación virtual}

Figura 9. Identidad visual de la Estrategia Azulejo

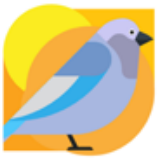

E4 - AZULEJO

Educación virtual

Fuente: Elaboración propia.

Tabla 23. Descripción detallada de la Estrategia Azulejo

\begin{tabular}{|l|l|}
\hline \multicolumn{2}{|c|}{ E4-Azulejo-Educación virtual } \\
\hline Descripción & $\begin{array}{l}\text { Esta estrategia busca crear y ejecutar un plan de educación dirigido a todos los involucrados en } \\
\text { los procesos turísticos actuales y futuros. La estrategia se enfoca en todos los actores, ya sean } \\
\text { ciudadanos colombianos, extranjeros, entes gubernamentales o prestadores de servicios. Se } \\
\text { busca crear contenido audiovisual que será presentado de acuerdo con el perfil de cada usuario } \\
\text { en una plataforma de educación virtual. }\end{array}$ \\
\hline Tipo & Educación y divulgación \\
\hline $\begin{array}{l}\text { Impacto } \\
\text { organizacional }\end{array}$ & $\begin{array}{l}\text { Aporta de forma directa a los objetivos estratégicos de promoción turística y busca que se } \\
\text { cumplan los lineamientos, la legalidad, la calidad y el control del sector turístico mediante el } \\
\text { entrenamiento actualizado y la certificación de todos los actores. }\end{array}$ \\
\hline $\begin{array}{l}\text { Requisitos de } \\
\text { implementación }\end{array}$ & $\begin{array}{l}\text { Compromiso desde los altos funcionarios del Ministerio de Comercio, Industria y Turismo } \\
\text { para adelantar el Plan. } \\
\text { Garantizar partidas presupuestarias a las iniciativas y un plan financiero de largo plazo. }\end{array}$ \\
\hline $\begin{array}{l}\text { Origen de la } \\
\text { estrategia }\end{array}$ & $\begin{array}{l}\text { Hallazgos: H01, H04, H07. } \\
\text { Motivadores: M01, M02, M03. }\end{array}$ \\
\hline
\end{tabular}

Fuente: Elaboración propia. 
Tabla 24. Detalle de las iniciativas de la Estrategia Azulejo

\begin{tabular}{|c|c|c|l|}
\hline \multirow{2}{*}{ Estrategia } & $\begin{array}{c}\text { ID_ } \\
\text { iniciativa }\end{array}$ & \multicolumn{1}{|c|}{$\begin{array}{c}\text { Nombre de la } \\
\text { iniciativa }\end{array}$} & \multicolumn{1}{c|}{ Descripción de la iniciativa } \\
\hline \multirow{2}{*}{$\begin{array}{c}\text { Estrategia E4 } \\
\text { Azulejo }\end{array}$} & $\mathrm{P} 4.1$ & $\begin{array}{l}\text { Selección, via- } \\
\text { bilidad técnica y } \\
\text { económica }\end{array}$ & $\begin{array}{l}\text { Recopilación, análisis y selección de propuestas para la } \\
\text { plataforma de educación virtual operada y gestionada por un } \\
\text { tercero. }\end{array}$ \\
\cline { 2 - 4 } & $\mathrm{P} 4.2$ & $\begin{array}{l}\text { Generación de con- } \\
\text { tenido (por actor) }\end{array}$ & $\begin{array}{l}\text { Creación de contenido específico por actor: ciudadano, presta- } \\
\text { dor, Gobierno. }\end{array}$ \\
\cline { 2 - 4 } & $\mathrm{P} 4.3$ & $\begin{array}{l}\text { Construcción de } \\
\text { un módulo de } \\
\text { comunicaciones } \\
\text { institucionales }\end{array}$ & $\begin{array}{l}\text { Creación de un módulo de comunicaciones internas para los } \\
\text { actores de la plataforma. }\end{array}$ \\
\hline
\end{tabular}

Fuente: Elaboración propia.

\subsubsection{E5 - Rupícola - Mejoramiento de experiencia del turista}

Figura 10. Identidad visual de la Estrategia Rupícola

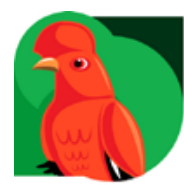

\section{E5 - RUPÍCOLA}

Mejoramiento de la

experiencia del turista

Fuente: Elaboración propia.

Tabla 25. Descripción detallada de la estrategia rupícola

\begin{tabular}{|l|l|}
\hline \multicolumn{2}{|c|}{ E5-Rupicola-Mejoramiento de experiencia del turista } \\
\hline Descripción & $\begin{array}{l}\text { Esta estrategia está encaminada a mejorar la experiencia de viaje de los turistas (nacionales o } \\
\text { extranjeros) gracias a la incorporación de nuevas tecnologías en algunas etapas o actividades } \\
\text { de su línea de experiencia. }\end{array}$ \\
\hline Tipo & Mejoramiento de proceso \\
\hline $\begin{array}{l}\text { Impacto } \\
\text { organizacional }\end{array}$ & $\begin{array}{l}\text { Un alto impacto en indicadores como “GOAL - 19. Satisfacción del visitante y su intención de } \\
\text { recomendar y repetir la visita", que a su vez es comparable con lo que se propone en otras na- } \\
\text { ciones pertenecientes a la ocDE, con lo cual se puede visibilizar internacionalmente la apuesta } \\
\text { del Gobierno en el turismo. }\end{array}$ \\
\hline $\begin{array}{l}\text { Requisitos de } \\
\text { implementación }\end{array}$ & $\begin{array}{l}\text { Implementación de la arquitectura de referencia planteada como base en la Estrategia } \\
\text { Alianza con proveedores de telecomunicaciones móviles. } \\
\text { Esquema de contratación por adquisición de servicios de terceros. }\end{array}$ \\
\hline $\begin{array}{l}\text { Origen de la es- } \\
\text { trategia }\end{array}$ & \begin{tabular}{l} 
Hallazgos: H02, H06 y H07-Motivador H1. \\
\hline
\end{tabular}
\end{tabular}

Fuente: Elaboración propia. 
Tabla 26. Detalle de las iniciativas de la Estrategia Rupícola

\begin{tabular}{|c|c|c|c|}
\hline Estrategia & $\underset{\text { iniciativa }}{I D_{-}}$ & Nombre de la iniciativa & Descripción de la iniciativa \\
\hline \multirow{6}{*}{$\begin{array}{l}\text { Estrategia } \\
\text { E5 Rupícola }\end{array}$} & P 5.1 & Cobro revertido & $\begin{array}{l}\text { Cobro revertido de datos o de datos patrocinados, es- } \\
\text { to con el fin de que todos los usuarios puedan acceder } \\
\text { a la aplicación sin importar si tienen plan de datos en } \\
\text { su dispositivo móvil. }\end{array}$ \\
\hline & P 5.2 & Tecnologías disruptivas & $\begin{array}{l}\text { Proyecto de realidad aumentada para reconocimiento } \\
\text { de flora y fauna en su polígono (ubicación). }\end{array}$ \\
\hline & P 5.3 & Descuentos por experiencia & $\begin{array}{l}\text { Mecanismo de fidelización georreferenciado del } \\
\text { turismo en Colombia con el fin de que el turista } \\
\text { pueda conocer cuáles experiencias disponibles se en- } \\
\text { cuentran cerca de donde está ubicado y pueda recibir } \\
\text { excelentes descuentos. }\end{array}$ \\
\hline & P 5.4 & $\begin{array}{l}\text { Sistemas de recomendación } \\
\text { para los destinos }\end{array}$ & $\begin{array}{l}\text { Modelo de recomendación por intereses y/o destino } \\
\text { de viaje. }\end{array}$ \\
\hline & P 5.5 & $\begin{array}{l}\text { Sistema de análisis de experien- } \\
\text { cias por sentimientos }\end{array}$ & $\begin{array}{l}\text { Análisis de los comentarios y PQRS con el fin de ana- } \\
\text { lizar la percepción de los turistas. }\end{array}$ \\
\hline & P 5.6 & $\begin{array}{l}\text { Datos abiertos para la comuni- } \\
\text { dad y API Marketplace }\end{array}$ & $\begin{array}{l}\text { Generación de API para la comunidad como mecanis- } \\
\text { mo para estimular el emprendimiento y la relación } \\
\text { eficiente entre instituciones. }\end{array}$ \\
\hline
\end{tabular}

Fuente: Elaboración propia.

\section{Implementación de la estrategia}

En esta sección se muestra una vista previa de la implementación de la Estrategia Colibrí, para lo cual se ha generado un prototipo con el fin de utilizar técnicas visuales que ayuden a que los tomadores de decisiones puedan ver la materialización de la estrategia y se efectúen las aprobaciones requeridas para un proyecto de transformación con este prototipo.

\subsection{Prototipo de experiencia del usuario}

La navegación en el prototipo fue desarrollada con base en los patrones de diseño interactivo propuestos por MacDonald (2019), en el que se desarrolló un flujo de interacción por medio del cual se pudiera generar experiencia de usuario tanto para el ciudadano como para los funcionarios de gobierno locales y nacionales.
Figura 11. Prototipo funcional de aplicación móvil

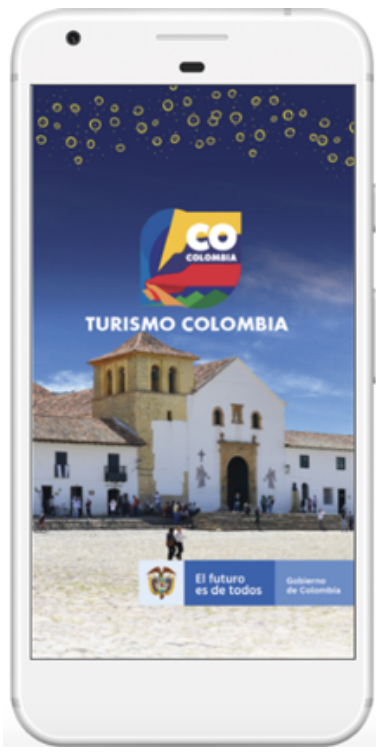

Fuente: Elaboración propia. 
Para interactuar con el prototipo, por favor, ingrese a la siguiente dirección web: https:// marvelapp.com/be $81 \mathrm{hbe} /$ screen/56460703

\subsection{Arquitectura de software de la solución}

En esta sección se define la arquitectura de referencia para el desarrollo de la aplicación que soportará la implementación de las estrategias propuestas anteriormente. Esta arquitectura se basa en los conceptos de sistemas distribuidos y se acoge a la estructura planeada por Burns (2018).

Debido a la alta concurrencia que se espera para la plataforma y a la expectativa de que esta pueda evolucionar en el tiempo bajo diferentes requerimientos de negocio, se propone una arquitectura de microservicios y separación en la que el frontend y el backend se encuentran separados y se busca la distribución de todos los componentes con el fin de tener cargas de trabajo elásticas que puedan soportar altas concurrencias en ciertas temporadas y decrecer en momento de inactividad.

Con el propósito de cumplir los acuerdos de disponibilidad $(99,95 \%)$, se planteó que toda la aplicación corra sobre la nube pública de un proveedor de infraestructura como servicio que debe ser seleccionado por la entidad responsable.

La descripción técnica detallada de esta arquitectura planeada será parte integral de un próximo artículo, en el que se profundizará sobre su implementación y el impacto en los resultados.

Figura 12. Esquema de arquitectura de la solución propuesta

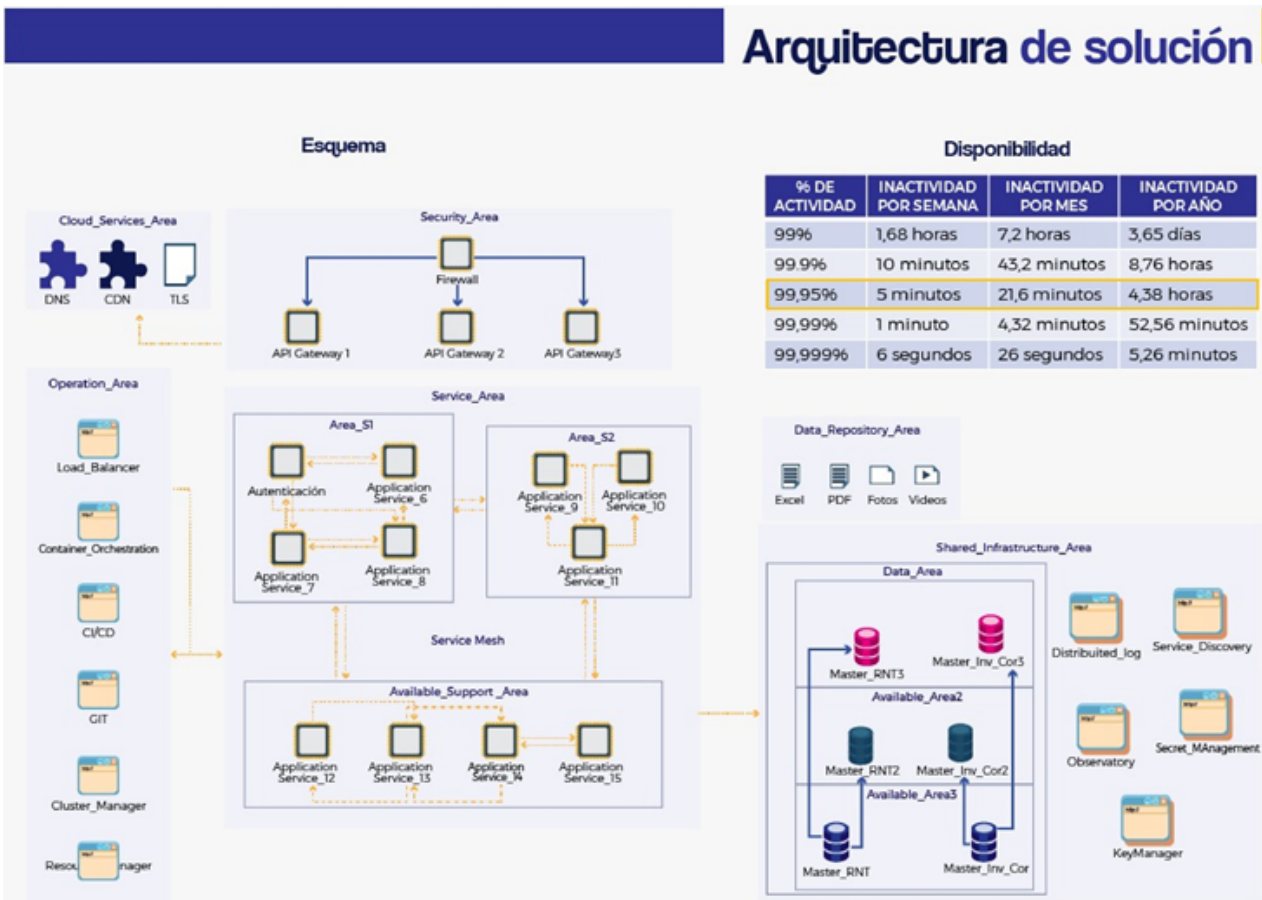

Fuente: Elaboración propia. 


\section{Conclusiones y recomendciones}

1. Es importante que los discursos y el deseo de los gobiernos se materialicen en planes estratégicos que se puedan llevar a cabo por medio de proyectos como este. La visión de gobierno ha de alinearse con los motivadores de negocio del empresariado con el fin de que se produzcan las transformaciones que el país necesita. Este proceso debe ser cíclico y su objetivo debe consistir en buscar mejoras continuas que lleven al país por las sendas del alto crecimiento y a convertirse en una nación más desarrollada.

2. Las iniciativas académicas deben encaminarse a resolver los problemas sociales y económicos que posee cada país, también han de ayudar a los gobiernos a alcanzar esos objetivos comunes de la sociedad.

3. El aprovechamiento de las tecnologías de la información será vital para el mejoramiento de la calidad de vida de los ciudadanos y en la promoción de las industrias claves del país.

4. El Plan de Transformación propuesto genera una visión clara de cómo ejecutar la estrategia, pues en él se muestra un mapa de ruta para que todos los actores puedan colaborar en conjunto con el fin de aumentar el desarrollo y la promoción del sector empresarial de las naciones.

5. Es importante que en temas de tecnología se pase de la retórica y de los planes a su ejecución, dado que los ciudadanos requieren ver los resultados.

6. El impulso del sector turístico requerirá un trabajo mancomunado en la generación de talento, tecnología y procesos ágiles y eficientes, que estén enmarcados en la normativa del país, con el fin de poder aprovechar la cuarta Revolución Industrial en pro de todos los ciudadanos.

\section{Referencias}

Burns, B. (2018). Designing distributed software. Sebastopol, CA: O'Reilly.

CITUR. (10 de mayo de 2019). Estadísticas nacionales. http://www.citur.gov.co/estadisticas\#gsc. tab $=0$

CityApp. (2019). Colombia Mapa. https:// itunes.apple.com/co/app/colombia-mapa/ id $423960898 ? \mathrm{mt}=8$

Colombia Travel. (2019). Mobile Apps. https:// colombia.travel/en. Consultado el 17 de mayo de 2019.

Congreso de Colombia. (26 de julio de 1996). Ley 300 de 1996. Por la cual se expide la Ley General de Turismo y se dictan otras disposiciones. Diario Oficial n. ${ }^{\circ} 42845$, del 30 de julio de 1996. http:// www.secretariasenado.gov.co/senado/basedoc/ ley_0300_1996.html

. (18 de agosto de 1999). Ley 527 de 1999. Por medio de la cual se define y reglamenta el acceso y uso de los mensajes de datos, del comercio electrónico y de las firmas digitales, y se establecen las entidades de certificación y se dictan otras disposiciones. Diario Oficial n. ${ }^{\circ} 43673$, del 21 de agosto de 1999. http://secretariasenado.gov. co/senado/basedoc/ley_0527_1999.html

. (22 de noviembre de 2006). Ley 1101 de 2006. Por la cual se modifica la Ley 300 de 1996-Ley General de Turismo y se dictan otras disposiciones. Diario Oficial n. ${ }^{\circ} 46461$, del 23 de noviembre de 2006. http://secretariasenado.gov. co/senado/basedoc/ley_1101_2006.html

. (31 de diciembre de 2008). Ley Estatutaria 1266 de 2008. Por la cual se dictan las disposiciones generales del habeas data y se regula el manejo de la información contenida en bases 
de datos personales, en especial la financiera, crediticia, comercial, de servicios y la proveniente de terceros países y se dictan otras disposiciones. Diario Oficial n. ${ }^{\circ} 47219$, del 31 de diciembre de 2008. http://www.secretariasenado.gov.co/senado/ basedoc/ley_1266_2008.html

. (10 de julio de 2012). Ley 1558 de 2012. Por la cual se modifica la Ley 300 de 1996-Ley General de Turismo, la Ley 1101 de 2006 y se dic$\tan$ otras disposiciones. Diario Oficial n. ${ }^{\circ} 48487$, del 10 de julio de 2012. http://www.secretariasenado.gov.co/senado/basedoc/ley_1558_2012.html

. (17 de octubre de 2012). Ley Estatutaria. 1581 de 2012. Por la cual se dictan disposiciones generales para la protección de datos personales. Diario Oficial n. ${ }^{\circ} 48587$, del 18 de octubre de 2012. http:/www.secretariasenado.gov.co/senado/ basedoc/ley_1581_2012.html

(26 de diciembre de 2012). Ley 1607 de 2012. Por la cual se expiden normas en materia tributaria y se dictan otras disposiciones. Diario Oficial n. ${ }^{\circ} 48655$, del 26 de diciembre de 2012. http://www.secretariasenado.gov.co/senado/ basedoc/ley_1607_2012.html

. (6 de marzo de 2014). Ley 1712 de 2014. Por medio de la cual se crea la Ley de Transparencia y del Derecho de Acceso a la Información Pública Nacional y se dictan otras disposiciones. Diario Oficial n. ${ }^{\circ}$ 49084, del 6 de marzo de 2014. http://www.secretariasenado.gov.co/senado/ basedoc/ley_1712_2014.html

. (28 de diciembre de 2018). Ley 1943 de 2018. Por la cual se expiden normas de financiamiento para el restablecimiento del equilibrio del presupuesto general y se dictan otras disposiciones. Diario Oficial n. ${ }^{\circ}$ 50820, del 28 de diciembre de 2018, p. 1. http://www.suin-juriscol.gov.co/ viewDocument.asp?ruta=Leyes/30036049

. (25 de mayo de 2019). Ley 1955 de 2019. Por el cual se expide el Plan Nacional de Desarro1lo 2018-2022. "Pacto por Colombia, pacto por la equidad". Diario Oficial n. ${ }^{\circ} 50964$, del 25 de mayo 2019. http://www.secretariasenado.gov.co/ senado/basedoc/ley_1955_2019.html

(27 de diciembre de 2019). Ley 2010 de 2019. Por medio de la cual se adoptan normas para la promoción del crecimiento económico, el empleo, la inversión, el fortalecimiento de las finanzas públicas y la progresividad, equidad y eficiencia del sistema tributario, de acuerdo con los objetivos que sobre la materia impulsaron la Ley 1943 de 2018 y se dictan otras disposiciones. Diario Oficial n. ${ }^{\circ} 51179$, del 27 de diciembre de 2019. http://secretariasenado.gov.co/senado/ basedoc/ley_2010_2019.html

Constitución Política de Colombia de 1991. http:// www.secretariasenado.gov.co/senado/basedoc/ constitucion_politica_1991.html

Corporación Colombia Digital. (2018). Plan Estratégico de las Tecnologías de la Información (PETI) 2019-2022. Bogotá, D.C.: MincIT.

DNP. (2018). Plan Nacional de Desarrollo 20182022. Bogotá, D. C.: DNP. https://www.dnp.gov. co/DNPN/Paginas/Plan-Nacional-de-Desarrollo. aspx

Dupeyras, A. y MacCallum, N. (2013). Indicators for measuring competitiveness in tourism: A guidance document [OECD Tourism Papers, 2013/02]. París: OECD Publishing. http://dx.doi. org/10.1787/5k47t9q2t923-en

Fondo Nacional de Turismo (FONTUR). (2012). Plan de Desarrollo Turístico Sostenible del Departamento de Boyacá. http://www.citur. gov.co/upload/publications/documentos/162. Plan_de_desarrolo_turistico_sostenible_del_departamento_de_Boyaca.pdf

. (26 de diciembre de 2016). Manual de Presupuesto FONTUR. https://www.fontur.com. co/aym_image/files/MAGNE55-MANUAL_ DE_PRESUPUESTO_FONTUR_1_291216.pdf

Rev. Turismo y Sociedad, vol. XXVIII, enero-junio 2021, pp. 151-185 
(18 de enero de 2019). Informe Anual 2018. http://www.fontur.com.co/aym_document/ aym_informe_anual/2018/INFORME_ANUAL_ FONTUR_2018.pdf

GSD. (31 de mayo de 2013). Estudio de conectividad de la red de pueblos patrimonio. http://www. citur.gov.co/upload/publications/documentos/229. ESTUDIO_DE_CONECTIVIDAD_DE_LA_ RED_DE_PUEBLOS_PATRIMONIO.pdf

Instituto Colombiano de Normas Técnicas y Certificación (Icontec). (2012). Norma Técnica Colombiana NTC 5854. Accesibilidad a páginas web. Bogotá, D. C.: Icontec.

Kale, V. (2019). Digital transformation of enterprise architecture. Boca Ratón, Florida: Taylor $\&$ Francis.

MacDonald, D. (2019). Practical UI patterns for design systems: Fast-track interaction design for a seamless user experience. New York: Apress Media.

McKinsey \& Co. (2012). Diagnóstico, visión y estrategias del sector de turismo a nivel nacional y regional. Bogotá: FONTUR.

Ministerio de Comercio, Industria y Turismo (Mincit). (28 de diciembre de 2015). Resolución 3860 de 2015. Por la cual se reglamenta el cumplimiento de las Normas Técnicas Sectoriales expedidas por las Unidades Sectoriales de Normalización para las actividades del denominado Turismo de Aventura y la Sostenibilidad Turística. Diario Oficial n. ${ }^{\circ}$ 49762, del 21 de enero de 2016. https://normativa.colpensiones.gov.co/colpens/ docs/resolucion_mincomercioit_3860_2015.htm

(17 de marzo de 2016). Circular 3 de 2016. Diario Oficial n. ${ }^{\circ} 49819$, del 18 de marzo de 2016.

(2019). Plan Sectorial de Turismo

2018-2022: "Por un turismo que construye pais”. Bogotá: Mincit. https://www.academia.
edu/37607682/Plan_Nacional_Sectorial_del_Turismo_2018_-2022

Ministerio del Interior y de Justicia. (28 de enero de 2010). Decreto 235 de 2010. Por el cual se regula el intercambio de información entre entidades para el cumplimiento de funciones públicas. Diario Oficial n. ${ }^{\circ} 47606$, del 28 de enero de 2010. https://www.funcionpublica.gov.co/eva/ gestornormativo/norma.php?i=38743

Ministerio de Tecnologías de la Información y las Comunicaciones (MinciT). (31 de diciembre de 2015). Resolución 3564 de 2015. Por la cual se reglamentan los artículos 2.1.1.2.1.1, 2.1.1.2.1.11, 2.1.1.2.2.2, y el parágrafo 2 del artículo 2.1.1.3.1.1 del Decreto 1081 de 2015 (Publicación de información en la web). Diario Oficial n. ${ }^{0} 49829$, del 30 de marzo de 2016. http://www.bogotajuridica. gov.co/sisjur/normas/Norma1.jsp?i=66249

Observatorio Colombiano de Ciencia y Tecnología. (2012). Plan Estratégico Departamental de Ciencia, Tecnología e Innovación (PEDCTI) Boyacá 2022. La ciencia, la tecnología y la innovación al servicio del desarrollo regional. Bogotá, D. C.: Departamento Administrativo de Ciencia, Tecnología e Innovación (Colciencias), Gobernación de Boyacá y Observatorio Colombiano de Ciencia y Tecnología. https://minciencias.gov.co/sites/ default/files/upload/paginas/pedcti-boyaca.pdf

OECD. (25 de mayo de 2018). Países de la OCDE acuerdan invitar a Colombia como miembro número 37. OECD. https://www.oecd.org/countries/colombia/oecd-countries-agree-to-invitecolombia-as-37th-member.htm

Presidencia de la República de Colombia. (10 de enero de 2012). Decreto Ley 019 de 2012. Por el cual se dictan normas para suprimir o reformar regulaciones, procedimientos y trámites innecesarios existentes en la Administración Pública. Diario Oficial n. ${ }^{\circ}$ 48308, del 10 de enero de 2012. http://www.secretariasenado.gov.co/senado/ basedoc/decreto_0019_2012.html 
(22 de noviembre de 2012). Decreto 2364 de 2012. Por medio del cual se reglamenta el artículo $7^{\circ}$ de la Ley 527 de 1999, sobre la firma electrónica y se dictan otras disposiciones. Diario Oficial n. ${ }^{\circ} 48622$, del 22 de noviembre de 2012. https://www.funcionpublica.gov.co/eva/ gestornormativo/norma.php?i=50583

(27 de junio de 2013). Decreto 1377 de 2013. Por el cual se reglamenta parcialmente la Ley 1581 de 2012. Diario Oficial n. ${ }^{\circ} 48834$, del 27 de junio de 2013, p. 28. http://www.suin-juriscol.gov.co/viewDocument. asp?ruta $=$ Decretos $/ 1276081$

(13 de mayo de 2014). Decreto 886 de 2014. Por el cual se reglamenta el artículo 25 de la Ley 1581 de 2012, relativo al Registro Nacional de Bases de Datos. Diario Oficial n. ${ }^{\circ}$ 49150, del 13 de mayo de 2014 , p. 89. http://www.suinjuriscol.gov.co/viewDocument.asp?id=1184150

. (26 de mayo de 2015). Decreto 1074 de 2015. Por medio del cual se expide el Decreto Único Reglamentario del Sector Comercio, Industria y Turismo. Diario Oficial n. ${ }^{\circ} 49523$, del 26 de mayo de 2015, p. 711. http://www.suin-juriscol. gov.co/viewDocument.asp?id=30019935

. (26 de mayo de 2015). Decreto 1078 de 2015. Por medio del cual se expide el Decreto Único Reglamentario del Sector de Tecnologías de la Información y las Comunicaciones. Diario Oficial n. ${ }^{\circ} 49523$, del 26 de mayo de 2015, p. 1.254. https://www.funcionpublica.gov.co/eva/ gestornormativo/norma.php?i=77888

(23 de febrero de 2016). Decreto 297 de 2016. Por el cual se reglamenta la exención del impuesto sobre las ventas para los servicios turísticos, establecida en el literal d) del artículo 481 del Estatuto Tributario, modificado por el artículo 55 de la Ley 1607 de 2012. Diario Oficial n. ${ }^{\circ} 49795$, de 23 de febrero de 2016, p. 32. http://www.suin-juriscol.gov.co/viewDocument. asp?ruta=Decretos/30021720
(7 de marzo de 2016). Decreto 415 de 2016. Por el cual se adiciona el Decreto Único Reglamentario del sector de la Función Pública, Decreto número 1083 de 2015, en lo relacionado con la definición de los lineamientos para el fortalecimiento institucional en materia de Tecnologías de la Información y las Comunicaciones. Diario Oficial n. ${ }^{\circ}$ 49808, del 7 de marzo de 2016. https://www.alcaldiabogota.gov.co/sisjur/normas/ Norma1.jsp $\mathrm{i}=65564 \& \mathrm{dt}=\mathrm{S}$

(14 de febrero de 2017). Decreto 229 de 2017. Por el cual se establecen las condiciones y requisitos para la inscripción Registro Nacional de Turismo y se modifican en su integridad las secciones 1,2 y 3 del Capítulo 1 del Título 4 de la Parte 2 del Libro 2 del Decreto 1074 de 2015, Reglamentario del Sector Comercio, Industria y Turismo. Diario Oficial n. ${ }^{\circ}$ 50147, del 14 de febrero de 2017. https://www.funcionpublica. gov.co/eva/gestornormativo/norma.php?i=79382

(14 de marzo de 2017). Decreto 431 de 2017. Por el cual se modifica y adiciona el Capítulo 6 del Título 1 de la Parte 2 del Libro 2 del Decreto número 1079 de 2015, en relación con la prestación del Servicio Público de Transporte Terrestre Automotor Especial, y se dictan otras disposiciones. Diario Oficial n. ${ }^{\circ} 50175$, del 14 de marzo de 2017, p. 4. http://www.suin-juriscol.gov. co/viewDocument.asp?id=30030420

(18 de enero de 2018). Decreto 90 de 2018. Por el cual se modifican los artículos 2.2.2.26.1.2 y 2.2.2.26.3.1 del Decreto número 1074 de 2015-Decreto Único Reglamentario del Sector Comercio, Industria y Turismo. Diario Oficial n. ${ }^{\circ}$ 50480, del 18 de enero de 2018, p. 6. http://www.suin-juriscol.gov.co/viewDocument. asp?id=30034466

. (1. ${ }^{\circ}$ de noviembre de 2018). Decreto 2063 de 2018. Por el cual se modifican los artículos 2.2.4.1.1.6, 2.2.4.1.1.10, 2.2.4.1.2.1, 2.2.4.1.2.2, 2.2.4.1.2.3, 2.2.4.1.2.4 y 2.2.4.1.3.4 del Decreto Único Reglamentario del Sector Comercio, 
Industria y Turismo, Decreto número 1074 de 2015. Diario Oficial n. ${ }^{\circ} 50764$, del $1 .^{\circ}$ de noviembre de 2018, p. 15. http://www.suin-juriscol.gov. co/viewDocument.asp?id=30035934

. (15 de noviembre de 2018). Decreto 2119 de 2018. Por medio del cual se reglamenta la prestación del servicio de alojamiento turístico y se modifican la Sección 12 del Capítulo 4 del Título 4 de la Parte 2 del Libro 2 y el parágrafo del artículo 2.2.4.7.2 del Decreto 1074 de 2015, Decreto Único Reglamentario del Sector Comercio, Industria y Turismo. Diario Oficial n. ${ }^{\circ} 50778$, del 15 de noviembre de 2018, p. 7. http://www.suinjuriscol.gov.co/viewDocument.asp?id=30035940

Quiñones, F. A. (2019). Guía ilustrada de avifauna Colombia. Bogotá: Wildlife Conservation Society.
Revista Dinero. (13 de julio de 2018). Balance del sector turismo en Colombia. https://www.dinero. com/pais/articulo/balance-del-sector-turismo-encolombia-2018/260070

SITUR. (2018). Indicadores de turismo Boyacá 2018. Tunja: SITUR Boyacá. http://www.situr.boyaca.gov.co/indicadores-de-turismo-boyaca-2018/

UN. (s. f.). Sustainable Development Goals. 17 Goals to transform our world. https://www.un.org/ sustainabledevelopment/

UNWTO. (s. f.). Digital transformation. https:// www.unwto.org/digital-transformation

WTO. (2019). Global-and-regional-tourismperformance. https://www.unwto.org/global-andregional-tourism-performance 